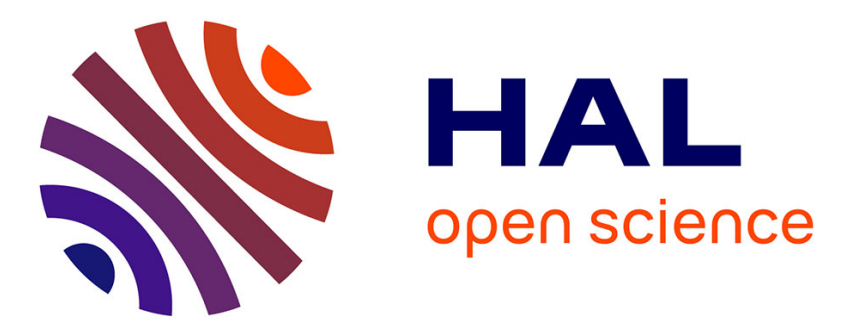

\title{
Why /r/ is not a special, empty consonant in Japanese Thomas Pellard
}

\section{To cite this version:}

Thomas Pellard. Why $/ \mathrm{r} /$ is not a special, empty consonant in Japanese. Journal of East Asian Linguistics, 2016, 25 (4), pp.351-383. 10.1007/s10831-016-9147-4 . hal-01356834v3

\section{HAL Id: hal-01356834 \\ https://hal.science/hal-01356834v3}

Submitted on 5 Oct 2016

HAL is a multi-disciplinary open access archive for the deposit and dissemination of scientific research documents, whether they are published or not. The documents may come from teaching and research institutions in France or abroad, or from public or private research centers.
L'archive ouverte pluridisciplinaire HAL, est destinée au dépôt et à la diffusion de documents scientifiques de niveau recherche, publiés ou non, émanant des établissements d'enseignement et de recherche français ou étrangers, des laboratoires publics ou privés. 


\title{
Why $/ r /$ is not a special, empty consonant in Japanese
}

\author{
2016, Journal of East Asian linguistics 25(4), doi: 10.1007/s10831-016-9147-4
}

Thomas PELLARD

CNRS (CRLAO)

\begin{abstract}
In recent work on Japanese phonology, $/ \mathrm{r} /$ has been argued to be a unique consonant in the Japanese phonological system, characterized by its default, unmarked and featureless nature. These peculiar features have been claimed to derive from the original epenthetic status and the late historical phonologization of $/ \mathrm{r} /$ in Japanese. However, a review of all the relevant evidence shows that there is actually no solid basis for that hypothesis, which proves to be not only inadequate, but also directly falsified by the data. No $r$-epenthesis process can be reconstructed in earlier Japanese, and / $\mathrm{r}$ / cannot be analyzed as a unique, default-empty consonant.
\end{abstract}

Keywords: Japanese; Phonology; Liquids; /r/; Underspecification; Markedness; Epenthesis

\section{Introduction}

The recent article "The phonology of Japanese /r/: A panchronic account" published by Laurence Labrune in the Journal of East Asian Linguistics (2014, 23: 1-25) argues for the unique status of the consonant $/ r$ in Japanese. Labrune's hypothesis of a unique status for $/ \mathrm{r} /$ in Japanese, henceforth $H_{r}$, synthesizes and develops previous research in both Japanese traditional linguistics and generative phonology. It comprises several different claims: / $\mathrm{r}$ / is claimed (a) to be an unmarked consonant, (b) to lack any phonological feature specification at the underlying level, and (c) to be an originally epenthetic consonant.

Together, these three characteristics are taken to uniquely define $/ r /$, a special default consonant in Japanese. The explanation for that unique status is sought in diachrony, ${ }^{1}$ and the $H_{r}$ proposes that $/ \mathrm{r} /$ was not a phoneme in proto-Japanese but the default realization of an empty onset in hiatus position, which was phonologized only later.

The $H_{r}$ presents many empirical claims about $/ \mathrm{r} /$ in Japanese and raises several important issues that need to be addressed. Besides its relevance for synchronic and diachronic studies on Japanese phonology, the $H_{r}$ has also wider typological and theoretical implications as well. In particular, it should be considered within the broader context of debates in theoretical phonology about underspecification, markedness, and epenthesis.

Nevertheless, the $H_{r}$ is open to challenge on both the-

1 Hence the subtitle "a panchronic account." The use of "panchronic" is however idiosyncratic here and does not refer to the program of Panchronic Phonology by Hagège \& Haudricourt (1978), which aims at formulating universal laws of sound change. oretical and empirical grounds. In the following, I shall reexamine all the arguments brought up by the $H_{r}$ concerning the phonetic properties, the distribution pattern, the frequency, the phonological and morphophonological behavior of $/ \mathrm{r} /$, and add additional evidence from L1 acquisition data and the typology of consonant epenthesis. The evidence purporting to support the $H_{r}$ does not actually corroborate that hypothesis, and even sometimes directly refutes it. The evidence adduced by the $H_{r}$ can be shown to be overstated, not uniquely characterizing $/ \mathrm{r} /$, amenable to alternative explanations, or simply inaccurate or wrong. Morever, both the methodology and the argumentation suffer from important limitations and inadequacies, in particular the absence of a systematic comparison with other consonants and the scantiness of quantitative and statistical evidence. The hypothesis that $/ r$ / is a special empty consonant in Japanese has thus to be rejected, and alternative accounts should be preferred.

\section{Phonetic properties}

\subsection{Variability}

The $H_{r}$ first presents phonetic arguments for the unique featureless status of $/ \mathrm{r} /$. Japanese $/ \mathrm{r} /$ is said to exhibit a wide array of contextual, stylistic, sociolinguistic, and dialectal $^{2}$ realizations, and that variability is tacitly inter-

2 Labrune (2012: 92) states that [ 3$]$ is the "most common realization of /r/ in some Ryûkyûan dialects." To the best of my knowledge, there is not a single Ryukyuan variety where this is true, and no dialect has ever been reported to possess such a lateral fricative (Uemura 1997; Karimata 1999; personal fieldnotes). The symbol [3] was sometimes used in an ad hoc manner in older descriptions to transcribe the Southern Ryukyuan fricative vowel 
preted as deriving from its lack of phonological specification. Notwithstanding its alleged variability, it is commonly agreed that / $\mathrm{r}$ / in Japanese is consistently voiced, apical, alveolar or post-alveolar, with a short or weak closure (Akamatsu 1997: 105-116, Saitō 2003: 11, Vance 2008: 89 ). The existence of such invariant features for $/ \mathrm{r} /$ that, cover laryngeal setting, manner, stricture, and place, directly contradicts the emptiness argued for by the $H_{r}$.

Another Japanese consonant that should be considered together with $/ \mathrm{r} /$ is $/ \mathrm{h} /$. It is important to note that the consonant $/ \mathrm{h} /\left(<{ }^{*} p\right)$ has actually more contextual allophones than $/ r /,{ }^{3}$ since it can be realized as $[\mathrm{h}],[\phi],[\mathrm{c}]$, or even $[\mathrm{x}],[\mathrm{x}]$, or $[\mathrm{h}]$, depending on the context (Saitō 2003, Labrune 2012: 69). Some abstract analyses even include [p] as an allophone of the same phoneme, especially in geminates (McCawley 1968: 7778, Labrune 2012: 70). If we follow the logic of the $H_{r}$ that "a wide range of phonetic realizations is suggestive of the unmarked status" (Labrune 2014:3) of a consonant, then $/ \mathrm{h} /$ should be considered as even less marked than /r/, which runs counter to the $H_{r}$.

\subsection{Other characteristics}

The description of / $r$ as "the shortest of all Japanese consonants" (Labrune 2014: 3 ) is a truism: The basic realization of $/ \mathrm{r} /$ is a tap, i.e., a "momentary" (Catford 2001: 67 ) sound defined by a "short closure" and a "brief contact between the articulators" (Ladefoged \& Maddieson 1996: 230-231). Whether $/ \mathrm{r} /$ is the shortest consonant of Japanese also depends on one's stance about the zero consonant /'/ posited by the $H_{r}$ (see below): If /'/ has no substance and is empty, one wonders what its duration is, and whether $/ \mathrm{r} /$ can be said to be shorter than zero (l'/).

Though / $\mathrm{r}$ / is said to fail to exhibit "any significant influence on the neighboring segments" (Labrune 2014:3), no actual data is presented and no comparison is made with other consonants. That claim is thus unsubstantiated.

\section{Distribution pattern}

The distribution pattern of $/ \mathrm{r} /$ in Japanese is noteworthy for its well-known restrictions. Though the $H_{r}$ interprets these constraints as evidence for the unique unmarked status of $/ r /$, distributional restrictions are

(otherwise variously noted as $[\mathrm{z}],\left[{ }_{\mathrm{z}}\right],\left[{ }^{\mathrm{z}_{\mathbf{i}}}\right],\left[{ }^{\mathrm{z}_{\mathbf{i}}}\right],[\mathrm{l}]$ ), not $/ \mathrm{r} /$, due to the lack of an official adequate IPA symbol. The typical realization of $/ \mathrm{r} /$ in virtually all Ryukyuan varieties is an alveolar tap similar to that of Japanese.

3 It also exhibits more dialectal variation, especially if, as the $H_{r}$ does (Labrune 2014: 10), we include Ryukyuan, where it corresponds to $[\mathrm{p}],\left[\mathrm{p}^{\mathrm{h}}\right],\left[\mathrm{p}^{\mathrm{p}}\right],\left[\mathrm{p}^{\phi}\right],[\phi],[\mathrm{f}],[\mathrm{M}],[\mathrm{c}]$, or $[\mathrm{h}]$ (Uemura 1997; Karimata 1999; personal fieldnotes). usually considered to target marked segments rather than unmarked ones (Trubetzkoy 1939: 236-237, Hockett 1955: 166-167, Flack 2007), so that in this case the data would suggest, to the contrary, that $/ \mathrm{r} /$ is marked in Japanese. That contradiction needs to be clarified one way or the other by the $H_{r}$.

In any case, the two pieces of evidence presented by the $H_{r}$, word-initial prohibition and co-occurrence restrictions, do not affect only $/ \mathrm{r} /$, but voiced obstruents as well. For the $H_{r}$, the existence of phonotactic constraints targeting $/ \mathrm{r} /$ demonstrates its unique unmarked status, while the fact that the same constraints apply to other consonants (the voiced obstruents) is deemed irrelevant, because those consonants are considered to be "heavily marked" (Labrune 2014: 15, fn. 11). This reasoning is a logical fallacy, both circular and selfcontradicting. For the sake of discussion, I will nevertheless examine below the evidence adduced by the $H_{r}$ in more detail.

\subsection{Word-initial prohibition}

In Old Japanese ${ }^{4}(\mathrm{OJ})$ "Yamato" native words, ${ }^{5} / \mathrm{r} /$ is banned from word-initial position, while the "empty onset" or "zero consonant" /'/ (Labrune 2014: $\left.5^{-6}\right)^{6}$ is restricted to that position, with no word-internal vowel sequence allowed $\left(\#^{\prime} V . C V, \dagger V . ' V, \operatorname{V.r} V, \dagger^{\prime}+r V\right) .{ }^{7}$ Though the $H_{r}$ does not mention it, this is not an absolute rule since there are several exceptions. Most Modern Standard Japanese (MSJ) exceptions result from the historical loss of an intervocalic consonant, but we already find in $\mathrm{OJ}$ forms with word-internal vowel sequences such as kai 'oar,' kui 'regret,' $\mathrm{ko}_{2} i$ 'lie down (infinitive),' oi 'age (infinitive),' uuru 'to plant (adnominal)' (Vovin 2009: 420-422, Frellesvig 2010: 39). ${ }^{8}$

Even if we set aside such counter-examples, contrary to the statement by the $H_{r}$ (Labrune $2014: 5^{-6}$ ), the ab-

4 I will follow common practice (Martin 1987; Vovin 2005a, 2009; Frellesvig 2010) and use "Old Japanese" instead of Labrune's (2014) "Ancient Japanese," and I will restrict its usage to refer to the language of the 8 th century only.

5 Sino-Japanese loanwords from the 8th century (Frellesvig 2010:

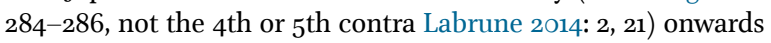
and contemporary loanwords do show initial $/ \mathrm{r} /$.

6 The $H_{r}$ refers to similar analyses by other scholars, but actually Hattori (1961) defines /'/ as a voiced laryngeal and not as a zero, Wenck (1966: 15) as a smooth onglide, and McCawley (1968: 8893) uses $/ 2 /$, which he treats as a glide.

7 In order to avoid confusion, the dagger symbol $(\dagger)$ indicates false forms, i.e., ungrammatical forms or forms expected from the rules under discussion but unattested, while the asterisk $\left(^{*}\right)$ marks reconstructed forms. The asterisk is also used to mark negative phonological constraints and constraint violations. $X$ indicates an unknown segment, and a dot marks syllable boundaries.

8 As noted by an anonymous reviewer, on an abstract morphophonological level, kui and uuru could be analyzed as respectively kuyi and uwuru because of their paradigmatic alternations with kuyu and uwe. 
sence of $/ \mathrm{r} /$ from word-initial position does not imply that $/ \mathrm{r} /$ is in complementary distribution with zero, at least in the usual sense of the term in phonology. The ban on word-initial position is valid for voiced obstruents $(/ b, d, g, z /)$ too, ${ }^{9}$ so that there is no exclusive relation between $/ \mathrm{r} /$ and zero: This feature is shared by more than one out of three OJ consonants.

The $H_{r}$ presents typological parallels for the ban of $/ \mathrm{r}$ / from word-initial position in Japanese (Labrune 2014: 22), but such evidence is irrelevant in trying to determine whether $/ \mathrm{r} /$ is a unique featureless consonant in Japanese. If the ban on liquids or rhotics in word-initial position is a typologically common phenomenon, then it must be due to either phonetic factors, with possibly a joint effect of diachronic changes, or to universal grammar. If there is a universal constraint on word-initial position that is independent of both the exact phonological features and the number of liquids in a language, it then logically follows that nothing can be inferred from that universal property about the specific characteristics of Japanese $/ r /$, except that it is indeed a liquid. A language-independent phonetic motivation for the ban on initial apical rhotics should be considered, like the relative articulatory difficulty of initiating a ballistic gesture word-initially (Kawahara 2015).

Besides this basic problem, the typological evidence quoted is empirically questionable. Unfortunately only a list of languages is given, without any references, and it remains unclear on what sources such claims are based. Basque seems to be a valid case, but that of proto-IndoEuropean is uncertain (Matasović 2012), even though the majority view seems to be that probably no root should be reconstructed with initial * $r$.

Proto-Austronesian is usually ${ }^{10}$ reconstructed with an initial * $r$ in a handful of words (Blust \& Trussel 2010). ${ }^{11}$ Though * $r$ is indeed rare in initial position (7 entries out of 1,446 in Blust \& Trussel 2010), this is also true of ${ }^{*} h$ ( 4 entries), ${ }^{*} \tilde{n}$ (3 entries), and ${ }^{*} z$ (10 entries). From this point of view, there is nothing unique about ${ }^{*} r$ in proto-Austronesian.

Initial $r$ is attested but rare in Burushaski (Anderson 1997), so that whether Burushaski can truly be said to "ban" $r$ in initial position is disputable. In any case, retroflex $y$ has an even more strongly restricted distribution than $r$ since "it occurs only in post-vocalic position, i.e., non-initially" (Anderson 1997: 1026). Here again, $r$ shows no unique property.

Concerning proto-Dravididian, the ban is on all alveo-

9 There is a single exception, the mimetic word $b i_{1} s i-b i_{1} s i$ 'sniffling' (Man'yōshū 5.892).

10 The alternative system reconstructed by Wolff (2010) does not include any ${ }^{*} r$, in which case proto-Austronesian is actually irrelevant to the discussion and cannot support the $H_{r}$.

11 Objections have been made to these reconstructions (Ross 1992). I thank an anonymous reviewer for pointing this out to me. lars and retroflexes, not just rhotics (Krishnamurti 2003: 92). Proto-Australian, if a valid case at all, has yet to be reconstructed, but word-initial * $r$ can be reconstructed in proto-Pama-Nyungan (Alpher 2004), although many modern Australian languages do not allow word-initial liquids or coronals altogether (Hamilton 1996: 213-227).

As for Altaic, many scholars reject the hypothesis that it is an actual language family (Georg 2003; Vovin 2005 b), though it is indeed well known that the Turkic, Mongolic, Tungusic, and Koreanic languages have no initial $r$ in their native lexicons. Yet, it is all word-initial liquids and nasals that are banned in most Turkic languages (Johanson 1998: 31). Proto-Mongolic, like many of its daughter languages, did not allow word-initial * $r$, *l, *̌̌, and * $\eta$ (Svantesson et al. 2005: 26-30, 124; Nugteren 2011: 73). In the Tungusic language Manchu, not only $r$ but $\eta$ too is banned from initial position, because of a sound change ${ }^{*} y>g / w$ (Cincius 1975-1977). In Korean, the liquid $l$ is not the only consonant banned from initial position, since it is also true of $\eta$, and also of $z, \beta$, and $\gamma$ in Middle Korean. The Middle Korean voiced fricatives are usually thought to be secondary developments from intervocalic lenition (Lee \& Ramsey 2011: 136-149), but they certainly did not arise from nothing.

Logically, it cannot be argued that the above cases involve several different "unique" empty consonants. Nothing can be concluded except that, in some languages, some consonants do not appear in word-initial position, probably for phonetic and historical reasons, and that $r$ sometimes just happens to be one of these. The $H_{r}$ assumes that if $r$ is banned from initial position in a language, then $r$ is probably a late development in that language. There is however no such evidence, and the argument here is begging the question. Alternative diachronic explanations, like the possibility that initial $r$ underwent a sound change, either shift or deletion, need to be considered (see Section 9).

\subsection{Co-occurrence restrictions}

A restriction on the co-occurrence of $/ \mathrm{r} /$ is presented by the $H_{r}$ in support of the hypothesis of the special status of that consonant. It is claimed that there can be only one $/ r$ / within a stem, especially a verb stem. That constraint should state a further condition on adjacency, otherwise the numerous examples such as arapare- 'appear,' karamar- 'get entangled,' muragar- 'flock,' etc., would falsify it. In any case, the following Old, Early Middle (EMJ), and Late Middle (LMJ) Japanese examples do not obey the constraint, even in its modified formulation: ${ }^{12}$

12 Non-exhaustive list obtained from Nakamura et al. (1982-1999) and Miyajima et al. (2014). Examples of compounding, reduplication, ideophones and other interjections were excluded. 
(1) a. irare- 'be irritated'13 (EMJ)

b. irarag- 'be prickly, rough' (EMJ)

c. $p i_{1} r o_{2} r$ - 'to spread' (OJ)

d. arare 'hail' (OJ)

e. turara 'icicle' (EMJ)

f. wirori yururi 'hearth' (LMJ)

The existence of a few mimetic words such as rerorero 'grumbling' or rorirori 'restless' that violate the phonotactic constraint against identical consonants in mimetic roots (Hamano 1998) is also adduced as evidence in favor of the $H_{r}$. The explanation that "/r/ is phonologically transparent" (Labrune 2014: 4, fn. 3) given by the $H_{r}$ is however surprising. One then wonders why such examples are not more numerous if they indeed do not violate phonotactic constraints at the underlying level. These counter-examples actually refute the idea that $/ \mathrm{r} /$ is transparent, since the relative paucity of such words suggests, on the contrary, that they do violate some constraint(s). From a logical point of view, the $H_{r}$ cannot use both co-occurrence restrictions and exceptions to such restrictions as evidence for the unique status of $/ \mathrm{r} /$, otherwise it turns into an unfalsifiable tautology.

The $H_{r}$ actually makes opposite claims one after the other. After stating that "identical consonants cannot occur twice in a mimetic root" (Labrune 2014: 4, fn. 3), the $H_{r}$ claims that the "coocurrence restriction is also operative in $\mathrm{OJ}$ nouns and other parts of speech, to the exception of mimetics" (Labrune 2014: 7). Obviously, both statements cannot be correct.

Furthermore, it must be noted that in spite of the contrary statement by the $H_{r}$ concerning verb stems (Labrune 2014: 14, fn.10), the constraint against cooccurrence is not limited to $/ \mathrm{r} /$ but affects the majority of Japanese consonants. In particular, stems with two voiced obstruents are virtually non-existent in the Yamato lexicon. ${ }^{14}$ For both voiced obstruents and $/ \mathrm{r} /$, a straightforward explanation can be proposed: Most roots are disyllabic, and since neither voiced obstruents nor $/ \mathrm{r} /$ can appear word-initially, there is usually at most one of these per root. The fact that stems with two glides or two occurences of $/ \mathrm{n} /$ are rare, even though they are not banned from initial position is thus only more remarkable. The only attested examples seem to be the following ones: $:^{15}$

13 Contrary to the claim by the $H_{r}$ (Labrune 2014: 7,14 ) that iraru is ill-formed, it is the conclusive form of EMJ 'be irritated.'

14 Within the $H_{r}$, the zero consonant l'/ too cannot occur twice within a (non-compound) word since it can only appear in wordinitial position.

15 Data obtained from Nakamura et al. (1982-1999) and Miyajima et al. (2014). Here again, cases of compounding, reduplication, ideophones and other interjections were excluded.
(2) a. yaya 'somewhat' (EMJ)

b. yayo-si 'numerous' (EMJ)

c. $\mathrm{yo}_{2} \mathrm{yo}_{2} \mathrm{~m}$ - 'get decrepit' (OJ)

d. wawake $_{2}$ ' 'tatter' (OJ)

e. nana 'seven' (OJ)

f. nani 'what' (OJ)

g. nuno 'cloth' (EMJ)

The constraint is thus not only valid for other consonants, but it is even more strictly enforced than for $/ \mathrm{r} /$. Such constraints should be considered in the light of the general avoidance of co-occurrence of similar consonants within a stem, which can be interpreted as the result of Obligatory Contour Principle (OCP) effects on place-homorganic consonants (Kawahara et al. 2006). The fact that $/ \mathrm{r} /$ too is subject to OCP constraints suggests that it is not featureless but specified for features that can be targeted by constraints.

\section{Frequency}

\subsection{Methodological remarks}

Frequency data can reveal interesting properties, but caution should be exercised with secondhand data. A frequency count of consonants presupposes a categorical analysis, usually in terms of phonemes, but little information is provided about the exact analysis adopted within the $H_{r}$. This is crucial in the case of the zero onset /'/ and of the approximant /y/, since some studies quoted by the $H_{r}$ consider /y/ not as an onset but as a medial glide following /'/, e.g., [jama] 'mountain' is analyzed as /'yama/ and [oja] 'parent' as /'o'ya/. As a result, $/ y /$ does not even appear in the frequency tables of consonants in those studies but is merged with /'/, whose frequency increases consequently. Labrune (2012: 88) classifies $/ \mathrm{y} /$ as a consonant, which presumably could mean that it is not a medial preceded by /'/, but no clear statement is given within the $H_{r}$.

The treatment of long vowels is also not trivial under the strictly binary ${ }^{16}$ model of prosodic units in Japanese (Labrune 2012:161-166). In that model, long vowels are analyzed as a full vowel followed by a deficient mora $(/ \mathrm{R} /)$ containing an underspecified vocalic nucleus but no onset. ${ }^{17}$ This amounts to saying that there is a zero onset /'/ in the second mora, which as a result would greatly increase the frequency of $/ \%$. The exact stance

16 That model is strictly but not perfectly binary since the onset slot of morae can branch into a main onset and a palatalizing element /y/ (Labrune 2012: 88, ex. 31), but not the nucleus.

17 See the isomorphism between an onsetless vowel and the second mora of long vowels in Labrune (2012: 162), the only difference being presumably the specification vs. underspecification of the 
of the $H_{r}$ on these matters needs clarification, and the frequency counts should be redone accordingly. In the following, I will consider onset consonants only, excluding moraic (coda) consonants as well as /y/ in tautosyllabic /Cy/ sequences. Syllable-initial occurrences of /y/ are analyzed as onsets, i.e., [jama] as /yama/ rather than /'yama/, long vowels as tautosyllabic /VV/ nuclei, and heterogeneous and/or heterosyllabic vowel sequences as $/ \mathrm{V}^{\prime} \mathrm{V} /$. $^{18}$

The $H_{r}$ draws attention to the frequency of consonants in the lexicon of the Japanese language at different historical stages. However, the complete lexicon of a language cannot be directly observed. The existence of productive compounding in a language implies that it has an infinite number of potential words, but even if we exclude compounds from consideration, no dictionary can be guaranteed to contain all neologisms, loans, rare jargon, and other idiosyncrasies of a language. This is even truer in the case of ancient languages, where the corpus of surviving written documents is limited and inevitably contains gaps. We can only observe a sample of the lexicon of a language, and the true frequencies in the ideal complete lexicon can only be inferred.

Any observation of the frequency of a consonant in a sample corpus will thus provide a single possible value of its true frequency in the complete lexicon, but such a point estimate depends on the characteristics of the sample, and different samples provide different values. Any observation from a sample is thus subject to some error, and there is no indication of how good the obtained estimate is. While the $H_{r}$ relies on point estimates only, it is preferable to base inferences on confidence intervals (CI), i.e., ranges of plausible values that likely capture the true value we are interested in. Such intervals take into account the sampling variability, and they not only provide more reliable estimates than point values, but also indicate the precision of the estimates.

One way of obtaining CIs is the bootstrap resampling method (Efron \& Tibshirani 1993), which consists in randomly resampling with replacement the observed data, and which has no requirements about the distribution

vocalic nucleus: empty onset $/ \mathrm{R} /$

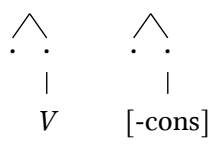

18 Words containing a coda or a long vowel could not always be properly handled since the original data used by Irie $(1996,2012)$ and Kokuritsu kokugo kenkyūjo (1984-1985) were not accessible. Thus, for instance, a three-mora $C_{1} V C_{2} V N$ word contributes to the frequency of its $C_{1}$ and $C_{2}$ components but has no $C_{3}$ component This creates small discrepancies between the number of words and the number of onset consonants when words are classified according to their length. The frequency of codas and long vowels is low enough (respectively $1.16 \%$ for two-mora nouns, $2.12 \%$ for three-mora nouns, and $2.98 \%$ for all nouns) not to significantly affect the results. of the population. All CIs reported in this article are 95\% CIs obtained by the percentile method on 10,00o bootstrap replications. The implementation by Canty \& Ripley (2016, version 1.3.18), after Davison \& Hinkley (1997) with the $R$ software (R Core Team 2015, version 3.2.3) was used. On graphs, CIs are indicated by error bars. ${ }^{19}$

\subsection{Frequency of $/ r /$ in word-internal position}

Japanese $/ \mathrm{r} /$ is claimed to be the "most frequent of all consonants in the word-internal position, i.e., not wordinitial, in two- and three-mora Yamato nouns" (Labrune 2014: 4). If true, this would indeed be a unique characteristic of $/ \mathrm{r} /$, but the data actually contradict that assertion.

As for three-mora words, no statement that $/ \mathrm{r} /$ is the most frequent consonant can be found in the source (Irie 1996) quoted by the $H_{r}$ (Labrune 2014: 4). Checking the frequency data in Irie (1996) for 6,329 wordinternal onsets in 3,233 three-mora Yamato nouns (Fig. 1) shows that the most frequent consonant is actually $/ \mathrm{k} /(13.98 \%$, CI [13.15\%, 14.85\%], $n=885)$, and not $/ \mathrm{r} /$ $(12.45 \%$, CI $[11.66 \%, 13.27 \%], n=788)$. The CI $[17,178]$ of the difference between the frequencies of the two consonants does not include zero, so that the hypothesis that $/ \mathrm{k} /$ is more frequent than $/ \mathrm{r} /$ can be accepted.

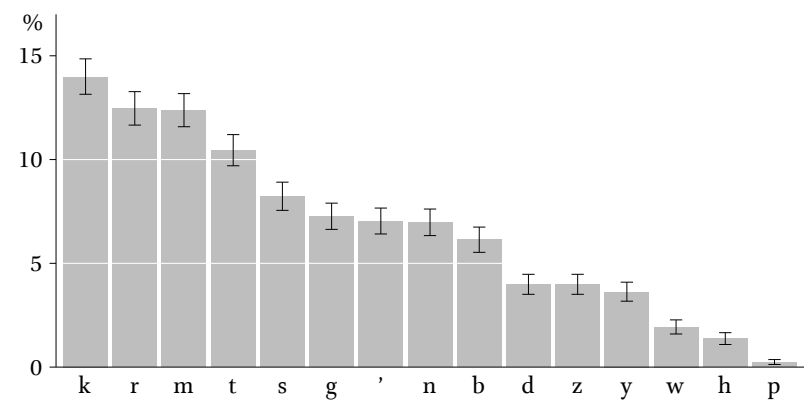

FIGURE 1 Relative frequency of 6,329 word-internal onset consonants in 3,233 three-mora Yamato nouns (Irie 1996).

Concerning two-mora words, $/ \mathrm{r} /$ is correctly quoted as the most frequent $(13.15 \%, n=146)$ among 1,110 onset consonants in word-internal position (Kokuritsu kokugo kenkyūjo $1984-1985 ;{ }^{20}$ Fig. 2). Still, the CI $([11.17 \%, 15.14 \%])$ of the frequency of $/ \mathrm{r} /$ largely (49.41\%) overlaps with that of $/ \mathrm{k} /([9.37 \%, 13.06 \%])$, the second most frequent consonant $(11.17 \%, n=124)$, and

19 Since the original data used by Irie $(1996,2012)$ and Kokuritsu kokugo kenkyūjo (1984-1985) were not accessible, I could only rely on simple frequency reports when computing CIs for MSJ nouns. Without a list of actual forms, I had to ignore possible dependencies between consonants within words. This is not desirable, but it has actually little effect on the results, and the mean frequencies calculated by the bootstrap method are close to the observed frequencies and do not exhibit a greater deviation from these than in the case of OJ nouns, for which I was able to use a list of actual forms.

20 There is a mistake in the reference title in Labrune (2014). 
the CI $[-55,10]$ of the difference between the frequency of the two consonants includes zero. This indicates that we cannot reject the null hypothesis that the greater frequency observed for $/ \mathrm{r} /$ is the result of chance, i.e., a random effect of sampling.

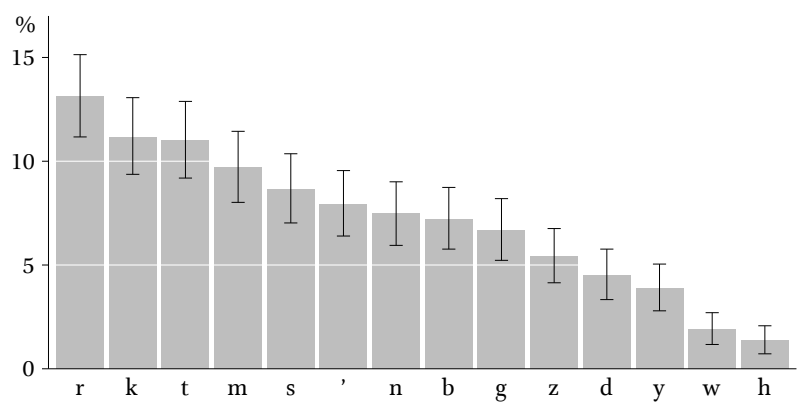

FIGURE 2 Relative frequency of 1,110 word-internal onset consonants in 1,134 two-mora Yamato nouns (Kokuritsu kokugo kenkyūjo 1984-1985).

If we take a more global look at the Yamato lexicon (Fig. 3), the data on 34,255 word-internal onsets of 13 ,015 nouns of various lengths in Irie (2012) shows that the most frequent consonant is here again $/ \mathrm{k} /(14.1 \%$, CI $[13.74 \%, 14.47 \%], n=4,831)$ and not $/ r /(13.52 \%$, CI $[13.17 \%, 13.89 \%], n=4,632) .{ }^{21}$ There is only limited overlap $(21.29 \%)$ between the CIs of the frequency of the two consonants, and the CI $[8,386]$ of the difference between the frequency of the two consonants does not include zero. The hypothesis that $/ \mathrm{k} /$ is more frequent than $/ r /$ in word-internal position can thus be accepted.

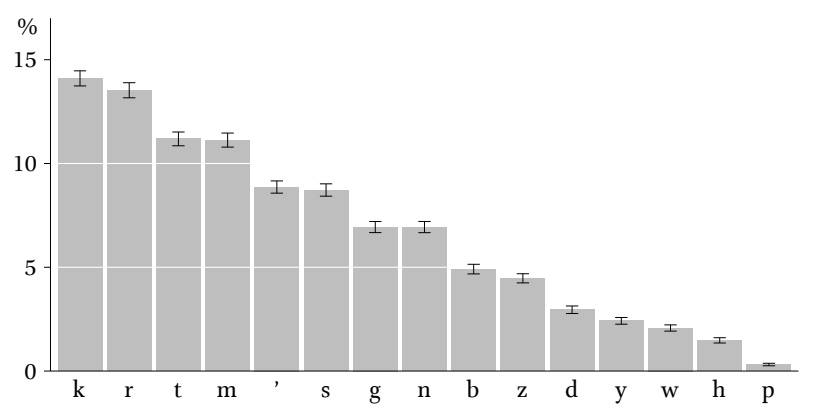

FIGURE 3 Relative frequency of 34,255 word-internal onset consonants in 13,015 Yamato nouns (Irie 2012).

It is also interesting to examine $\mathrm{OJ}$ too, since it is by definition more informative than MSJ about the historical status of consonants the $H_{r}$ is interested in. For this purpose, I used the lexical database of the Man'yōshu (759) in Miyajima et al. (2014), which contains 3,850 different OJ Yamato nouns and thus constitutes a reasonable sample of the OJ lexicon. ${ }^{22}$ Interestingly, as

21 These figures were obtained by substracting for each consonant its word-initial frequency (Irie 2012: 82, Table 6.2.2) from its total frequency (Irie 2012: 85, Table 6.2.8).

22 Eastern Old Japanese dialectal forms were removed when marked as such in the original database. Miyajima et al. (2014) do not distinguish words attested in phonograms from traditional readings of logographic spellings, which might potentially in- shown in Fig. 4, /r/ is found to be the fifth most frequent consonant only $(10.33 \%$, CI [9.75\%, 10.89\%], $n=$ $1,035)$, far behind $/ \mathrm{m} /$, the most frequent one $(13.71 \%$, CI $[13.03 \%, 14.39 \%], n=1,374)$. The CI of the difference between their frequencies $([248,430])$ does not include zero, which indicates that the difference observed is statistically significant.

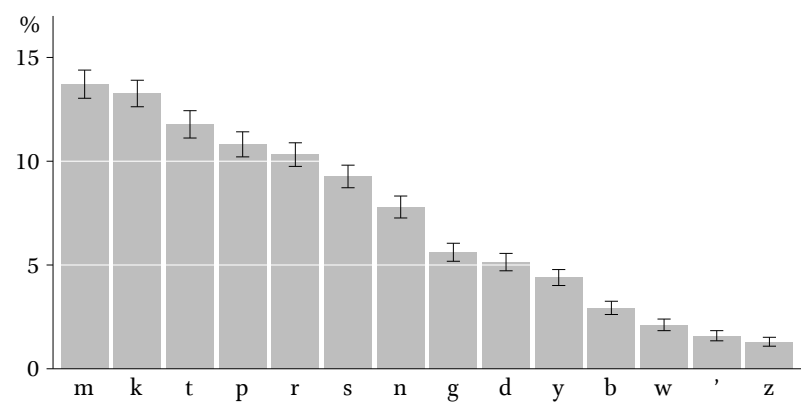

FIGURE 4 Relative frequency of 10,020 word-internal onset consonants in 3,850 OJ Yamato nouns in the Man'yōshū (Miyajima et al. 2014).

The surveys in Irie (2012) of lexical consonant frequencies in OJ (Man'yōshū), EMJ (Genji monogatari, early 11 th c.) and LMJ (Nippo jisho, 1603) similarly show that $/ \mathrm{r} /$ only ranks as respectively the fifth $(10.06 \%$, $884 / 8,787)$, third $(12.04 \%, 1,266 / 10,512)$, and second $(12.73 \%, 2,953 / 23,203)$ most frequent word-internal consonant in Yamato nouns. This confirms that the statement that $/ \mathrm{r} /$ was the most frequent consonant wordinternally in Yamato nouns is not true at any historical stage of Japanese. The frequency of word-internal / $\mathrm{r} /$ seems to increase with time, but this contradicts the $H_{r}$ 's view that $r$-epenthesis was a pre-OJ phenomenon.

\subsection{Distribution of $/ r /$ within words}

The $H_{r}$ makes another strong claim on the distribution pattern of $/ \mathrm{r} /$ within words in OJ, namely that " $/ \mathrm{r} /$ is more likely to appear toward the right edge of Yamato stems" (Labrune 2014: 4). The formulation of this hypothesis is ambiguous, and several different interpretations are possible. I propose to test them all.

First, the original version of the claim (Kuginuki 1982) can be stated as follows: In OJ, most occurrences $(88.4 \%)$ of $/ \mathrm{r} /$ are found in the rightmost (final) mora of "combinatory units." Assessing the empirical correctness of this claim is difficult for several reasons. There is no explicit definition given for "combinatory unit" (ketsugo tan'i), and though it seems to be more or less equivalent to "root," there are nevertheless many unsegmented forms in the data, like partially or fully reduplicated mimetics (e.g., yura-ra, ura-ura) and nominal

clude a few anachronistic forms that did not exist yet at the OJ stage. This should nevertheless not affect the overall frequency statistics in any significant manner. 
adjectives derived by suffixation (e.g., paru- $k a$, $\mathrm{OrO}_{2}-k a$ ). Also, the procedure for segmenting (or not segmenting) and counting such units is not discussed. As a consequence, the study by Kuginuki (1982) is not straightforwardly replicable.

The inclusion of suffixes is also problematic since they are neither stems nor roots and are thus not relevant to the question under study. Most importantly, both one- and two-mora items are included in the corpus when in fact they should not be, because of the bias they introduce in the data. Neither one- nor two-mora words can tell us anything that we don't already know, because of their size and of the ban on $/ \mathrm{r} /$ in initial position: The distributional bias of $/ r /$ they exhibit is by definition expected from the constraint against wordinitial /r/. One- and two-mora items represent as much as $43.27 \%$ of the whole data in Kuginuki (1982) and thus introduce an important distortion in the results. The focus should thus be on words at least three morae long.

Finally, no comparison is made with other consonants and such a comparison is not possible since only a list of items containing at least one $/ \mathrm{r} /$ is given.

Instead of the problematic data and procedure of Kuginuki (1982), I used a subset of the Man'yōshü data of Miyajima et al. (2014), restricted to three- and four-mora long nouns. Though the data is not restricted to roots, it does not suffer from segmentation problems and makes the analysis replicable.

First, if we calculate the number of occurrences of $/ \mathrm{r} /$ in final morae against all those in non-final morae, we find that out of 603 instances of /r/, 312 (51.74\%, CI $[50.18 \%, 53.32 \%])$ appear in a final mora. The lower bound of the $\mathrm{CI}$ is above $50 \%$, but not much higher. The frequency of $/ \mathrm{r} /$ in final morae is thus only marginally greater than in non-final morae. A detailed look at the data shows that for four-mora nouns, there are actually fewer instances of $/ \mathrm{r} /$ in the final mora $(175 / 376=$ $46.54 \%$, CI [44.31\%, 48.54\%]) than in non-final ones.

Alternatively, if we examine the number of occurrences of / $\mathrm{r}$ / in final morae as compared to those in nonfinal morae, but without lumping the latter together, we find that it is indeed true for both three- and fourmora words that most occurrences of $/ \mathrm{r} /$ are found in the last mora. However, the case of $/ \mathrm{r} /$ is not unique, and other consonants exhibit a similar distribution: / $\mathrm{b}, \mathrm{m}, \mathrm{p} /$ for three-mora nouns, and $/ \mathrm{m}, \mathrm{z} /$ for four-mora nouns (Fig. 5).

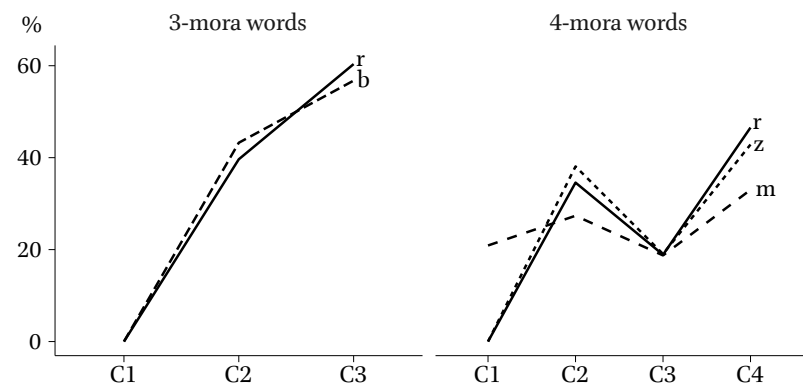

FIGURE 5 Relative frequency of position for onset consonants in 1,078 three- (left panel) and 1,209 four-mora (right panel) Yamato nouns in OJ (Miyajima et al. 2014). Only /r/ and those consonants exhibiting a broadly similar distribution appear on the figure.

A related hypothesis worth investigating is whether the number of occurrences of $/ r /$ consistently increases as we move rightward in a word, so that there are always more occurrences of $/ r /$ in the $n+1$ th mora than in the $n$th mora of a word. A necessary corollary question is whether other consonants exhibit a similar distribution or not. Figure 5 illustrates that indeed, within three-mora words, the frequency of $/ r /$ rises consistently towards its right edge. On the other hand, this is not the case in four-mora words, where there is a dip of frequency in the third mora position, so that there is no monotonic increase. ${ }^{23}$ In both cases, at least one other consonant can be found with a similar distribution pattern, so that the case of $/ r /$ is not unique.

Finally, we can test whether $/ \mathrm{r} /$ is the most frequent consonant in the rightmost mora of OJ nouns. Figure 6 shows that the most frequent consonant is $/ \mathrm{m} /(15.26 \%$, CI $[13.77 \%, 16.75 \%], n=349)$ and not $/ \mathrm{r} /(13.64 \%$, CI $[12.29 \%, 15.09 \%], n=312)$, but the CI $[-15,88]$ of the difference between the frequencies of the two consonants includes zero, so that the hypothesis that either $/ \mathrm{m} /$ or $/ \mathrm{r} /$ is more frequent than the other cannot be accepted.

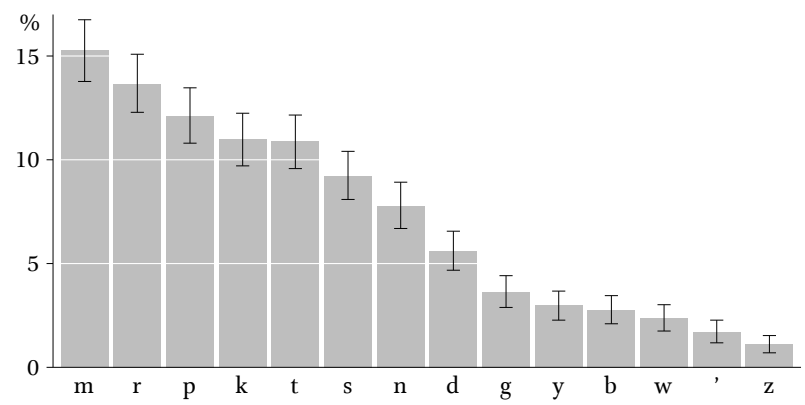

FIGURE 6 Relative frequency of onset consonants in the last mora of 3,85 o Yamato nouns in OJ (Miyajima et al. 2014).

23 Many four-mora nouns are compounds made up of two bimoraic stems, so that the third mora of the compound is actually the initial mora of the second member. This probably explains the dip in $/ r /$ frequency. 


\section{Phonological processes}

\subsection{Resistance to palatalization}

The resistance of $/ \mathrm{r} /$ to palatalization in mimetics is taken as evidence for the unmarked status of $/ \mathrm{r} /$ within the Japanese consonant system (Mester \& Itō 1989, Labrune 2014: 7-8). Still, alternative accounts are possible, and they do not appeal to formal markedness and underspecification, but to articulatory difficulty (Schourup \& Tamori 1992) or feature compatibility (Kurisu 2009). The $H_{r}$ only objects that such explanations cannot account for the other characteristics of / $\mathrm{r}$ / (Labrune 2014: 8 , fn. 8). I take this to imply that if, as is argued here, the other characteristics of $/ \mathrm{r} / \mathrm{can}$ be explained away or shown to be overstatements, then the alternative accounts of resistance to palatalization can be accepted and the markedness-based explanation rejected on the basis of parsimony.

A phonetic explanation for the resistance of $/ \mathrm{r} /$ to palatalization is particularly well-founded if we consider the cross-linguistic markedness of palatalized liquids and their diachronic instability (Hock 1991: 133135; Hall 2000; Hall \& Hamann 2010). The avoidance of palatalized rhotics in particular is grounded in articulatory phonetics since the invariant features of tongue posture for rhotics and for high front vocoids are antagonistic (Hall \& Hamann 2010).

It should also be noted that it is strictly impossible for $/ \mathrm{w} /$ to be palatalized, and neither can $/ \mathrm{y} /$ since it is a palatal. If we consider, like the $H_{r}$, that onsetless syllables actually contain a zero consonant /'/, then this zero consonant adds to the inventory of those that cannot be palatalized, unless onset $/ y /$ is reinterpreted as a medial glide and not a true onset. Those consonants are thus even more resistant to palatalization than $/ \mathrm{r} /$, since $/ \mathrm{ry} /$ sequences are licit in Japanese, even in Yamato forms. ${ }^{24}$ The avoidance of palatalized / $\mathrm{r} /$ is thus better viewed as a result of a violable constraint rather than of a structural impossibility (Kawahara 2015).

\subsection{Resistance to gemination}

Resistance of $/ \mathrm{r} /$ to gemination is also adduced by the $H_{r}$ as evidence for the lack of specification of / $\mathrm{r} /$ in Japanese, but a more detailed examination of the facts is needed. First, we should bear in mind that geminates are overall rare in the native uninflected lexicon of Japanese, and that they did not exist yet in OJ. Then, it is not only $/ \mathrm{r} /$, but also voiced obstruents, approximants, and $/ \mathrm{h} /$ that rarely undergo gemination in Japanese (Labrune 2012: 136). The crosslinguistically marked status

24 E.g., karyūdo 'hunter,' shiryūgoto 'backbiting,' koryā for kore=wa 'this=TOPIC' of geminate sonorants like $/ \mathrm{r} /$ can be explained as a natural consequence of their phonetic properties: Constriction duration is a major perceptual cue for distinguishing geminates, but sonorants have less clear-cut segmental boundaries, which makes a length opposition more difficult to perceive (Podesva 2002; Kawahara 2007). There is also an inherent antagonism between the momentary nature of a tap like $/ \mathrm{r} /$ and gemination. The rarity of geminated $/ r /$ in Japanese thus does not proceed from some abstract property specific to Japanese $/ \mathrm{r} /$ but from universal phonetic properties, and it therefore offers no real support to the $H_{r}$.

In the formation of mimetic adverbs in -ri with gemination, $(C) V C V$ bases give geminated $(C) V C_{i} C_{i} V-r i$ adverbs (bata $\rightarrow$ batta-ri 'with a bang'), but semi-geminated (prenasalized) (C) VNCV-ri in the case of a voiced consonant (boya $\rightarrow$ bon'ya-ri 'absentmindedly'), while $(C) \operatorname{VrV}$ bases give $(C) V r V$-ri adverbs without any gemination, like koro $\rightarrow$ korori 'without effort' (Mester \& Itō 1989). For the $H_{r}$, this suggests that Japanese $/ \mathrm{r} /$ is unspecified for place features since gemination or semi-gemination is considered to require the spreading of such a place feature (Mester \& Itō 1989). Though this lack of gemination is compatible with the $H_{r}$ 's hypothesis of / $\mathrm{r} /$ as completely featureless, it does not offer specific evidence for it. At best, it can support the hypothesis that $/ \mathrm{r} /$ lacks a place specification. Kawahara (2015) proposes instead a constraint ${ }^{*} \mathrm{Nr}$ against sequences of a mora nasal and $/ \mathrm{r} /$. That constraint is grounded in the "phonetic difficulty of implementing a ballistic tongue gesture for $/ \mathrm{r} /$ after the oral closure of a nasal."25 It is interesting to note that there is no attested Yamato (non-mimetic) word with an $/ \mathrm{Nr} /$ sequence.

Nevertheless, geminated $/ \mathrm{r} /$ is amply attested in both mimetic (barra-bara 'in disorder') and non-mimetic (karrāi 'spicy') emphatic forms (Schourup \& Tamori 1992: 137-138). Emphatic gemination of $/ \mathrm{r} /$ is most common in reduplicated mimetics such as yurru-yuru 'loose,' tsurru-tsuru 'smooth', sarra-sara 'rustle,' etc. Such forms cannot easily be dismissed since they are the result of a productive process. The resistance of $/ \mathrm{r} /$ to gemination is not as strong as stated by the $H_{r}$, and it thus does not support the special status of $/ r /$. Any structural account of the resistance of $/ \mathrm{r} /$ to gemination is unable to explain the existence of $r$-gemination since it asserts its impossibility.

25 As pointed out by an anonymous reviewer, only the release portion of the tap occurs when / $\mathrm{r}$ / follows /N/ (Vance 2008: 97), so that the gesture is not really ballistic in this environment. This can be interpreted as supporting the view that implementing a ballistic gesture is indeed difficult in such an environment. 


\subsection{Vowel coalescence in Ryukyuan}

The mention of vowel coalescence in Ryukyuan varieties (Labrune 2014: 10) is interesting, but these are not just dialects of Japanese. They are a group of at least five distinct languages which split from Japanese around 1,500 years ago (Pellard 2015, 2016) and exhibit a diversity comparable to that of the Romance languages. It is therefore safer not to make assumptions about Japanese on the basis of Ryukyuan, much as Spanish data should not be brought into the discussion of French synchronic phonology.

Nonetheless, the invisibility mentioned by the $H_{r}$ (e.g., /guruhan/ $\rightarrow$ gorohon 'far') is again not a unique property of $/ \mathrm{r} /$, but it is also shared by the laryngeal $/ \mathrm{h} /$ (e.g., /pataki-ha/ $\rightarrow$ patakehe 'field-ALLATIVE') in those Ryukyuan varieties (Lawrence 2000). This suffices to nullify again any claim of a special status of $/ \mathrm{r} /$.

\subsection{Instability and inertness}

Though the $H_{r}$ states that $/ \mathrm{r} /$ is "the most unstable of all Japanese consonants" (Labrune 2014: 7), no convincing empirical data are presented in support of that assertion. No quantitative data, but only a few anecdotal examples are listed, and no comparison is made with other consonants.

All examples of assimilation presented are of the form $r V C_{2}>C_{2} C_{2}$, but, as Kawahara (2015) notes, such anticipatory assimilation cannot be due to some specific property of Japanese $/ \mathrm{r} /$ since assimilating $C_{1} C_{2}$ sequences universally more often result in $C_{2} C_{2}$ than in $C_{1} C_{1}$ (Hock 1991: 63). The fact that $/ \mathrm{r} /$ is a target but not a source of assimilation is thus naturally expected in such examples, which therefore do not constitute evidence for the emptiness of $/ \mathrm{r} /$. On the other hand, examples of the type $C_{1} V r>C_{1} C_{1}$ are not found. Also, all examples presented involve the syncope of different vowels, but, even for the $H_{r}$, this does not imply that vowels are featureless in Japanese.

The case of contracted inflected forms with assimilation, such as nannai for naranai 'not become,' does not actually constitute conclusive evidence for the $H_{r}{ }^{26}$ This assimilation of $/ r /$ along with vowel syncope is restricted, as it only happens before /n/ but not before other coronals or nasals. Thus naritai 'want to become' does not yield †nattai, and narimasu 'become (polite)' does not yield †nanmasu. This process is also morphologically highly restricted, since it only happens at morpheme boundaries in inflected verb forms, and lexically restricted, since there are doublets such as tarinai tannai 'not suffice,' but not for karinai ( $†$ kannai) 'not borrow.' This process is therefore not purely phono-

26 See Ichimura (2006) for a detailed discussion of such forms. logical and does not support the inherent phonological instability of $/ \mathrm{r} /$.

Concerning examples like torite $>$ totte 'take,' it should be noted that it is only one example of a very general process widely known as onbin ('euphony') in Japanese linguistics (Frellesvig 2010: 191-199). This process has affected most other consonants as well, like in omopite $>$ omotte 'think' or motite > motte 'hold.' It thus cannot be used as evidence for the special status of $/ \mathrm{r} /$. Other examples listed are as sporadic as EMJ Nipita $>$ Nitta 'new field (surname),' OJ ki, gi, si > kiji 'pheasant,' OJ - amu $>-\bar{o}$ 'conjectural,' -te shimau > -chau 'completive auxiliary,' sumimasen > suimasen 'excuse me,' -nakereba > nakya 'if not,' etc. These are not regular changes and thus do not qualify as sound changes in the Neogrammarian sense of the term. ${ }^{27}$

Actually, $/ \mathrm{r} /$ is one of the most stable consonants in the history of the Japanese language from a traditional (Neogrammarian) point of view, since it has not been affected by a single regular sound change since at least the 8th century. This contrasts with changes such as $\mathrm{OJ} p>$ $h / \# \_, \mathrm{p}>w(>\varnothing) / V_{-} V, y>\varnothing\left|\_e, w>\varnothing\right| \_\{i \text {, }$ $e, o\}$, or the change from prenasalized obstruents to simple voiced ones (Martin 1987; Frellesvig 2010).

\section{Morphology}

\subsection{Verbal inflection and r-epenthesis}

The analysis of Japanese verb morphology is not a trivial matter, notwithstanding its relative simplicity and regularity. On the basis of alternations with zero, the $H_{r}$ endorses the view that the $/ \mathrm{r} /$ attested in several inflected forms is epenthetic, but this is precisely the locus of controversy. Several scholars have argued to the contrary that such suffix-initial consonants are better viewed as being part of the underlying form of the suffix (McCawley 1968: 93-10o, Shibatani 1990: 221-235). Still others have argued that both allomorphs are listed in the lexicon, and that there is thus neither epenthesis nor deletion (Ichimura 2006: 207-217). ${ }^{28}$ One strong argument against the epenthetic approach is that other consonants alternate with zero too, such as the causative suffix -sase $\sim$-ase or the hortative $-y \bar{o} \sim-\bar{o}$. The epenthesis hypothesis misses an important generalization and cannot account for all alternations in a unified fashion, in contrast with other approaches. There is thus no deci-

27 That is to say, changes that affect all occurrences of a segment in a certain phonetic or phonological environment without any lexical or morphological conditioning and that suffer no exception except loanwords and cases of analogy.

28 The last approach was the position of structuralists such as Bloch (1946) or Martin (1952). See also Otoguro (2009) for an interesting criticism of morpheme-based approaches to Japanese morphology. 
sive evidence in favor of the $H_{r}$ concerning $r$-epenthesis.

Japanese verbs that are newly formed on the basis of a (sometimes) truncated nominal stem all belong to the $r$-conjugation, ${ }^{29}$ e.g., English demonstration $>$ J. demo $>$ demor- 'march.' Apparently, this has not always been the case, as evidenced by examples like kozik- 'beg' < Sino-Japanese koziki 'beggar,' rikim- 'try hard, show a bold front' < Sino-Japanese riki 'strength,' or mokurom'plan' < Sino-Japanese mokuron 'plan' (Martin 1987: 673). While the $H_{r}$ analyzes the former process as phonological epenthesis of the unmarked segment $/ \mathrm{r} /$ between the stem and vowel-initial suffixes, the latter examples cannot be explained the same way.

A morphological account is actually possible, where new verbs are formed by analogy with the $r$-conjugation class, and are thus adjoined a root-final $/ \mathrm{r} /$. The $r$-class is the second most populated $(20.53 \%$, CI $[19.76 \%, 21.32 \%])$ one after the $e$-class $(31.78 \%$, CI $[30.88 \%, 32.65 \%])$, and well before the $i$-class $(2.49 \%$, CI $[2.19 \%, 2.8 \%]) .{ }^{30}$ However, the two vowel-stem classes have only $e$-and $i$-ending stems and thus cannot accommodate stems with other vowels, such as jiko 'accident' > jikor- 'have an accident.' No reference to the alleged phonological properties of $/ \mathrm{r} /$ is necessary.

A decisive counter-argument to the epenthesis hypothesis is that, even when their root ends with the same vowel, innovative $r$-conjugation verbs with a putatively epenthetic $/ r /$ do not belong to the same conjugation class as vowel-conjugation verbs, where the suffixinitial $/ r /$ is similarly claimed to be epenthetic. In other words, the $H_{r}$ cannot handle the fact that, even though both are claimed to exhibit the same epenthetic /r/, kopi > kopir-u (kopir-anai, kopit-te, etc.) 'photocopy' does not follow the same pattern as mi-ru (mi-nai, mi-te) 'see.'

The situation in $\mathrm{OJ}$ also requires more care. The $H_{r}$ (Labrune 2014: 11, Tab. 3) gives an overview of the verb paradigms of "ninth-century Japanese," but the forms are those of 8th-century OJ, with the exception of conclusive " $m i_{1} r u$," which does not exist and was most likely just * $m i_{1}$ (Vovin 2009: 595-597, Frellesvig 2010: 107). If we also safely ignore the optional imperative particle $\mathrm{yo}_{2} \sim \mathrm{ro}_{2}, / \mathrm{r} /$ is only present in the adnominal and realis forms, which might go back to a single origin (Whitman 2016). The consonant $/ r /$ is thus not as frequent in the basic inflectional forms of $\mathrm{OJ}$ as stated by the $H_{r}$.

Kawahara (2015) also reminds us of an important fact about the validity of evidence from Japanese verbal inflection patterns for phonology. Experimental stud-

29 Conjugation classes in Japanese are determined by the stem-final segment.

30 Calculated on the basis of 10,350 MSJ Yamato verbs in the UniDic (Den et al. 2007, unidic-mecab version 2.1.2) database. The database does not include productive compounds with the light verb suru 'do.' Pre-modern forms, orthographic variants and other duplicates were filtered out beforehand. ies have indeed repeatedly shown that native Japanese speakers cannot consistently replicate regular inflectional patterns with nonce words, which indicates that speakers do not conjugate verbs by applying rules or constraints to underlying forms but store inflected forms in their memories (Vance 1987, 1991; Batchelder 1999).

\subsection{Frequency of $/ r /$ in suffixes}

One more claim of the $H_{r}$ is that $/ \mathrm{r} /$ is "extremely frequent at the beginning of several [...] suffixes" (Labrune 2014: 6). ${ }^{31}$ Unfortunately, only a handful of examples is given, which is not convincing without a quantitative comparison with other consonants. The unique status of $/ r /$ regarding its frequency at the beginning of suffixes can only be established by showing that $/ \mathrm{r} /$ is more frequent than the other consonants. Moreover, some of the examples listed are problematic, like the "aspectual" -ri, actually the stative $-e_{(1)} r-i$, a reanalysis of a fused form of the existential verb ar-i with a preceding infinitive form $\left(-i_{(1)}\right)$, or -ru "passive, potential" and -reru "passive, potential, honorific," which are actually one and the same.

In order to properly verify the above claim, I compiled a list of all OJ suffixes in Vovin's (2005a, 2009) reference grammar. Case markers and particles, which are not true suffixes, Eastern Old Japanese dialectal forms, and vowel-only suffixes were excluded. On the other hand, suppletive allomorphs were all included, adding up to a total of 59 items. For vowel-initial suffixes, the vowel usually alternates with zero, which is problematic. First, I counted all initial consonants in the list including the longest form of each suffix, but excluding vowel-initial suffixes. Thus - $(a) k u$ 'nominalizer' is excluded and -(r)aye 'passive' is counted as an occurrence of initial /r/. As illustrated in Fig. 7, the most frequent consonant at the beginning of OJ suffixes is then not $/ \mathrm{r} /(5 / 36=13.89 \%$, CI $[2.78 \%, 25 \%])$ but $/ \mathrm{k} /(10 / 36=$ $27.78 \%$, CI $[13.89 \%, 41.67 \%])$. Second, I took the alternative approach to include the first (non-initial) consonant of vowel-initial suffixes, and thus to count the previously excluded $-(a) k u$ 'nominalizer' as an occurrence of $/ \mathrm{k} /$. In this case (Fig. 8), the frequency of $/ \mathrm{r} /$ rises $(11 / 59=18.64 \%$, CI $[10.17 \%, 28.81 \%])$, but only to reach that of $/ \mathrm{k} /(11 / 59=18.64 \%$, CI [10.17\%, 28.81\%]).

31 Within the argumentation of the $H_{r}$, if $/ \mathrm{r} /$ is the most frequent consonant in word-internal position stems, then its high frequency in suffixes should be naturally expected too, so that the case of suffixes would not constitute independent evidence. It is the reverse situation, i.e., an asymmetric pattern between stems and suffixes, that would be unexpected and would require an explanation. 


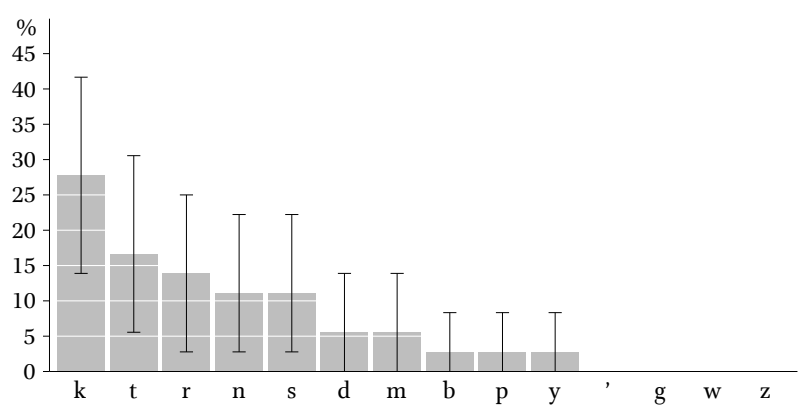

FIGURE 7 Frequency of the first onset consonant in 36 OJ suffixes (Vovin 2005a, 2009), excluding vowel-initial suffixes.

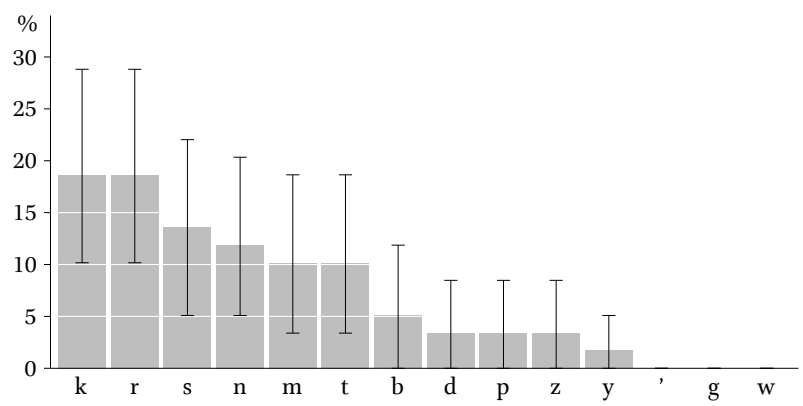

FIGURE 8 Frequency of the first onset consonant in 59 OJ suffixes (Vovin 2005a, 2009), including vowel-initial suffixes.

The extremely limited size of the corpus of suffixes does not permit drawing definitive conclusions about the significance of the differences observed in the frequencies of consonants. Nevertheless, whichever counting method is adopted, the claim that $/ \mathrm{r} /$ is "extremely frequent" at the beginning of OJ suffixes is not supported by the data. The derivational verb formatives reconstructed by Martin (1987: 671-672, 790-796) could also be brought into discussion, but here again $r$ formatives are not the most numerous, nor the most frequent in verb stems.

\subsection{First-mora reduplication in $\mathrm{OJ}$}

The $H_{r}$ (Labrune 1993: 15-16, Labrune 2014: 12) proposes to reverse Unger's $\left(1975: 57-5^{8}\right)$ theory about first mora reduplication in OJ. Instead of " $\mathrm{rO}_{2} \mathrm{gam}$ - 'bow' " $\mathrm{rO}_{2} \mathrm{ro}_{2} \mathrm{gam}$-'revere' > wogam- $\sim$ woro $_{2} \mathrm{gam}$-, the $\mathrm{H}_{\mathrm{r}}$ reconstructs ${ }^{* \prime} \mathrm{O}_{2} \mathrm{gam}-\sim{ }^{* \prime} \mathrm{O}_{2} \mathrm{O}_{2} \mathrm{gam}$ - and an $r$-epenthesis process. There are nevertheless several empirical problems with this proposal.

Contrary to the $H_{r}$ 's claim (Labrune 2014:12-13), both OJ wogam- and woro $_{2}$ gam- clearly had an initial glide $w$ distinct from the zero onset, and that consonant cannot be considered to be an artifact of transcription. The reality of the initial $w$ is uncontroversial and well supported by both textual and comparative evidence (Arisaka 1955: 636-641, Miyake 2003: 170, 194). For instance, in the $\mathrm{Ko}^{-}$ jiki (712), OJ wo is always transcribed by Chinese characters with an initial ${ }^{*} w$-, and $\mathrm{OJ} ' o$ by characters with an initial *?-The grapheme $w o$ is also always classified with $w a, w i$, and $w e$ in ancient syllabaries organized by initial consonant, where they are found at the same place as Sanskrit $v a$. Also, most Northern Ryukyuan varieties have $w u$ corresponding to OJ $w o$ vs. ? $u$ corresponding to OJ $o$, while Southern varieties have a correspondence $b u:: w o$ vs. $u:: o$ (Uemura 1997; Karimata 1999, personal fieldnotes).

The misunderstanding seems to come from the interpretation by the $H_{r}$ of the distinction between 'o and wo in $\mathrm{OJ}$ as a difference in the nuclear vowel rather than in the onset, i.e. ${ }^{\prime} o=/ \mathrm{o}_{1} /$ and $w o=/ \mathrm{o}_{2} /$. Since $o_{1}$ and $o_{2}$ are often thought to have differed in labialization, that interpretation might be valid, but it crucially misses the fact that it is $o_{1}$, and not $o_{2}$, which is reconstructed as labialized (Miyake 2003: 211-216, 233-238). ${ }^{32}$ This prevents the analysis of $\mathrm{OJ} w o$ as $/ \mathrm{o}_{2} /$. Analyzing the distinction between ' $o$ and wo in OJ as a vowel opposition would also be problematic from the point of view of later historical developments. Though the merger of $o_{1}$ and $o_{2}$ was completed by the end of the 1oth century, the syllables 'o and wo remained distinct in Middle Japanese until the 11th century (Frellesvig 2010). Further support for not interpreting $\mathrm{OJ} w o$ as representing $\mathrm{o}_{2}$ comes from the fact that, although the vowels $o_{2}$ and $a$ usually do not coexist within the same root (Frellesvig 2010: 44), there are several examples where $a$ coexists with $w o .{ }^{33}$

The reconstruction of ${ }^{*} \mathrm{O}_{2} \mathrm{O}_{2} \mathrm{gam}$ - with $r$-epenthesis to woro $_{2} \mathrm{gam}$ - is thus impossible: The base form is wogam-, and initial reduplication would have yielded †wowogam-. On the other hand, the changes ${ }^{*} r\left(>?^{*} j\right)$ $>\varnothing \mid \_i,{ }^{*} r(>w)>\varnothing / \ldots u$ and ${ }^{*} r>w / \ldots o$ posited by Unger (1975) can be viewed as natural assimilations through the development of homorganic glides. The change ${ }^{*} r>n / \ldots a$ posited by Unger (1975) is not without motivation, contrary to the statement by the $H_{r}$ (Labrune 2014: 12). It finds typological parallels within Algonquian (Bloomfield 1925), Gurage (Semitic, Kümmel 2007: 158), and Korean (Lee \& Ramsey 2011: 152-153).

\subsection{Suffixation of $/ r V /$ syllables and reduplication}

The $H_{r}$ proposes that suffixation of $-r V$ strings is ubiquitous in Japanese and that it proceeds from an iconic process of lengthening equivalent to reduplication (Labrune 1998, 2014: 13). According to the $H_{r}$, a root can be iconically lengthened to express almost anything ('state,' 'appearance,' 'manner,' 'deictic,' 'definiteness,' 'approximation,' 'intensive,' 'diminutive, 'hypocoristic,' 'theonym,' 'plurality,' 'subjectivity,' 'onomatopeia,' 'hyponym,' 'duration,' etc.), and that augmentation can

32 Hence the phonemicization of $\mathrm{Co}_{1}$ as $C w o$ by Unger (1975) and Frellesvig (2010).

33 For example awo 'blue,' kawor- 'float, smell,' sawo 'pole,' tawom'verb of unclear meaning,' mawos- 'say (honorific),' woka 'hill,' wopar- 'end,' etc. See Pellard (2013). 
proceed by insertion of default (though not fully predictable) segmental material or by full or partial reduplication, without any clear distinction. In other words, there is no semantic, prosodic, nor segmental fixed content (Labrune 1998: 101). Such an unconstrained analysis is hardly falsifiable and lacks predictive as well as explanatory power.

Due to space limitations, I cannot review every example in Labrune (1998), and I will thus only mention that in many cases, there is no basis for positing a suffix $-r V$ and there is no reduplicated variant attested. ${ }^{34}$ For verbs, the independent base is either not attested or the $-r$ - is simply the "endoactive" verbalizer, perhaps resulting from the grammaticalization of ar- 'be, exist,' reconstructed as *-ra by Unger (1975) and Martin (1987). ${ }^{35}$ Many other etymological comparisons isolating a suffix $-r V$ are problematic due to phonological and/or semantic reasons. ${ }^{36}$ Lastly, examples of the type $C V r V_{i} r V_{i}$ should be removed since they could actually involve partial reduplication of their final mora ${ }^{37}$ rather than $r V$ suffixation.

The only really relevant examples adduced by the $H_{r}$ are those where two patterns, one with $r$ and another with reduplication, are found. First, a bimoraic mimetic root can be either reduplicated or followed by -ri, e.g., soyo-ri soyo-soyo 'gently breezing.' However, the two processes are not fully equivalent: While reduplication derives nominal adjectives, manner adverbs, and nouns, $r i$-suffixation derives adverbs only. Concerning semantics, reduplication iconically expresses iterativity or durativity, but ri-suffixation expresses semelfactivity, perfectivity, and quiet ending of a movement (Hamano

34 For example, segmenting a base and a suffix $-r V$ is not possible in namari 'lead,' hokori 'dust,' madara 'spots,' etc., since there is no related base †nama, †hoko or †mada. There are no related reduplicated forms like †nama-nama, †hoko-hoko, †mada-mada either.

35 For instance maturap- 'celebrate' and kazarap- 'decorate' derive respectively from matur- and kazar-followed by the iterative/continuative suffix -ap- (Vovin 2009: 820-828), and positing an intervening "lengthener" $-r V$ is not justified.

36 Thus the comparisons hashira 'pillar' hashi 'bridge, ladder' or makura 'pillow' maki (mistakenly given as maku in Labrune 1998: 92) 'firewood,' are problematic since those pairs of words do not belong to the same historical tonal register. Examples such as kokoro 'heart, feeling' kakus- 'hide,' are far-fetched and not convincing. In some cases, more concrete etymologies can be proposed, like sasu 'sting' + ari 'ant' (Martin 1987: 519) rather than sasu 'sting' + ri 'unknown meaning' with an irregular vowel development for sasori 'scorpion.' Many other examples are problematic, like migi migiri 'right,' where the variant migiri is probably due to analogy with both the deverbal noun nigir- $i$ 'handful, fist' and hidari 'left,' or like the Aragusuku Ryukyuan form pikara, a mistake for pikarja (pïkar'a in Miyara 198o-1981 [1930]: 89, Vol. II) which comes from * pikari 'light' + -ja 'suffix for agent and animal nouns.'

37 See for example tawa-wa tawa-tawa 'drooping,' iyo-yo iyo-iyo 'more and more, at last,' niko-ko niko-niko 'smiling,' etc.
1998; Tamori \& Schourup 1999). ${ }^{38}$ This intrinsic semantic value of -ri also differs from the iconic value of fluidity associated with $/ \mathrm{r} /$ in mimetics, and it leads Hamano (1998) to conclude that this - $r i$ is a morpheme and not a sound-symbolic unit.

Another $-r V$ suffix is adduced by the $H_{r}$, the plural marker $-r a$, which also expresses approximation and endearment. However, the comparison with plural marking by reduplication does not demonstrate that the two are fully equivalent, since there seems to be no example of reduplication expressing approximation or endearment. Conversely, reduplication usually has the meaning of 'each, every' or 'all' (e.g., OJ kuniguni 'all countries,' Man'yōshū 20.4381, 20.4391), while -ra expresses a collective/associative meaning (e.g., OJ $\mathrm{Ko}_{7} \mathrm{si} \mathrm{no}_{2} \mathrm{Ki}_{1} \mathrm{mi}_{1}-\mathrm{ra}$ 'the lords of the country of Koshi,' Man'yōshū 18.4071). ${ }^{39}$

Lastly, the formative - $r a$ found after adjectival roots cannot be readily compared with reduplication. For instance, the example baka-rashii baka-baka-shii 'foolish' (Labrune 2014: 13) involves the adjective-forming suffix -rashii '-like, typical of' which first appeared in LMJ, long after / $r$ / had entered the phonological system of Japanese according to the $H_{r}$, so that it is not really relevant here. Second, while reduplicated roots such as aka-aka 'bright red' have an intensive meaning, this is not the case with $r a$-derivatives like aka-ra 'reddish, blushed.'40 Then, though we find numerous nominal adjectives following the pattern $X$-ra-ka, reduplicated $\dagger X$ $X$-ka forms are not permitted, which shows that - $r a$ and reduplication are not interchangeable iconic lengtheners. Also, formatives other than - $r a$ are found between an adjectival root and $-k a$, e.g., OJ tama-sa-ka 'occasional' (cf. EMJ tama-tama 'occasionally'), OJ $\mathrm{OrO}_{2}-\mathrm{So}_{2}{ }^{-}$ $k a$ 'neglectful' (cf. OJ $\mathrm{oro}_{2} k a$ 'id.,' EMJ oro-oro 'flustered'), OJ mutu-ma-ka 'intimate' (cf. OJ mutu-ma-si, OJ mutumutu-si 'id.'). It would be unrealistic to analyze all of these as iconic lengtheners.

\section{Acquisition}

Data from acquisition studies is relevant for the study of markedness, since unmarked segments are acquired before marked ones (Jakobson 1941), but the $H_{r}$ does not mention this issue. Ueda \& Davis (2001) summarize several studies that clearly establish that $/ \mathrm{r} /$ is acquired late by Japanese-speaking children, and Arai (2013) shows that $/ r$ is difficult to acquire. This is hardly compatible with the claim that $/ r /$ is the most unmarked consonant in Japanese.

38 Compare for instance koro-koro 'rolling over and over' and koro-ri 'rolling and falling (once, of an object not heavy).'

39 See Vovin (2005a: 91-109).

40 Cf. akara-woto ${ }_{2}$ me $_{1}$ (Kojiki 43) 'ruddy maiden,' not 'maiden with a bright red skin.' 
Japanese $/ r$ / is often substituted by other consonants in child speech, especially in initial position, but on the other hand no case of intrusive $/ \mathrm{r} /$ has been reported in the literature, and only intervocalic /d/ seems to be replaced by /r/ in child speech (Ueda \& Davis 2001). The analysis by Ueda \& Davis (2001) within the framework of Optimality Theory even posits a general constraint against $/ \mathrm{r} /$ as an onset, which is also incompatible with the $H_{r}$.

\section{Cross-linguistic evidence on $r$-epenthesis}

An important point not fully discussed by the $H_{r}$ is whether $r$-epenthesis is a cross-linguistically common and natural phenomenon. While a natural phonological phenomenon implies the existence of a phonetic motivation for it, "grounded in articulatory and perceptual properties of speech" (Blevins 2008: 126, 130), no such explanation is proposed for $r$-epenthesis by the $H_{r}$. The account by the $H_{r}$ thus remains highly speculative.

Though the $H_{r}$ cites the cases of English and Dutch as potential parallels (Labrune 2014: 19, fn. 6), it is contradicted by the thorough survey by Hall (2013). A review of all purported cases of $r$-epenthesis in the literature reveals that there is "very little solid cross-linguistic evidence for that process" (Hall 2013: 30). Epenthesis of $r$ is not only clearly not a phonologically natural phenomenon, but it also always presupposes an earlier stage of deletion of $r$ and alternation with zero. Similarly, McCarthy (1993: 190) observes that $r$-epenthesis does not imply that $/ \mathrm{r} /$ is the default consonant in English, and that " $r$ epenthesis is unnatural because epenthesis of $r$ is always historically secondary to deletion of $r$ from which it derives by reanalysis." Staroverov (2014) also reaches the conclusion that $r$-epenthesis (or "vowelsplitting" by $/ \mathrm{r} /$ ) is not expected, contrary to glide epenthesis. Even Uffmann (2007), quoted in support of the $H_{r}$, acknowledges that $r$-epenthesis is optimal only in cases where glide epenthesis is blocked, i.e., typically after low vowels. Japanese does not fit into that typology and is thus predicted not to exhibit $r$-epenthesis.

\section{Historical scenario}

There is decisive evidence that runs counter to the hypothesis of a late development of $r$ and its predictions. ${ }^{41}$ If $r$ were indeed originally an allophone of zero, there should be many cases where $r$ alternates with zero. How-

41 It is noteworthy that proponents of a genetic relationship between Japanese and Korean (Martin 1966; Whitman 1985, 2012) do not believe that their common ancestor lacked a phoneme ${ }^{*} r$. Since the Koreo-Japonic hypothesis is controversial, I will not discuss it further. ever, there are none. ${ }^{42}$ On the other hand, there are several examples in OJ where $s$ alternates with zero in pairs like ame $_{2}$ 'rain' paru-same 2 'spring rain,' ine 'rice' uru-sine 'nonglutinous rice.' Examples of alternations with other consonants have been proposed too, such as utur- yutur- 'move, pass' or ubatama nubatama 'blackberry lily's seed.'43

The complete absence of a single clear example of $r$ epenthesis in OJ and pre-OJ comparable to the above ones is a strong argument against the epenthesis scenario of the $H_{r}$. It nevertheless receives a confounding interpretation in Labrune (1993: 11), where it is argued that the very fact that there is no example of $r$ epenthesis is remarkable and demonstrates that $/ \mathrm{r} /$ is a special consonant, since it is the only one that is not subject to epenthesis. This overlooks the fact that there isn't any example of epenthesis of $/ \mathrm{b} /, / \mathrm{d} /, / \mathrm{g} /$, and $/ \mathrm{z} /$ either, it does not uniquely characterize $/ \mathrm{r} /$. The argument is also logically flawed: It cannot be argued at the same time that $/ \mathrm{r} /$ is epenthetic but also not epenthetic, and that in both cases this constitutes evidence for its special status. Direct evidence of $r$-epenthesis would fit the $H_{r}$, but the absence of epenthesis is also taken to support the $H_{r}$. The $H_{r}$, proposing to account for both something (the existence of $r$-epenthesis) and its contrary (the absence of $r$-epenthesis), is true under any circumstances, so that it is unfalsifiable. Needless to say, this argument has to be rejected on purely logical grounds.

According to the $H_{r}$ 's scenario, earlier vowel sequences would have evolved to $\dagger V r V$ through epenthesis. This is however falsified by ample textual evidence from OJ and internal reconstruction of proto-Japanese, where hiatus is always resolved by vowel elision or crasis (Unger 1975: 72-81, Russell 2003, Frellesvig 2008, Kupchik 2013), but never by $r$-epenthesis. ${ }^{44}$

\section{(3) Elision}
a. necessitive $-b e_{2^{-}}<u b e_{2}$ 'indeed' $m i_{1}+u b e_{2^{-}}>m i_{1} b e_{2^{-}}$'should look' $\left(\dagger m i_{1} r u b e_{2^{-}}\right)^{45}$
b. stative -tar-<-te 'gerund' + ar- 'be' $k i_{1} t e+a r->k i_{1}$ tar- 'has come' ( $\dagger k i_{1}$ terar- $)$
c. OJ bigrade verbs conclusive form $o k i_{2}+-u>o k u$ 'rise' $\left(\dagger o k i_{2} r u\right)^{46}$
d. lexical elision waga 'my' + imo 'beloved' > wagi $i_{1}$ mo (†wagarimo $)$

42 Except for the problematic cases in verbal morphology rejected above.

43 See Yamaguchi (1974) for a detailed survey, though alternations with zero are interpreted as deletions rather than insertions there.

44 The $H_{r}$ specifically argues for $r$-epenthesis between a stem and its affixes and not compounds. The list below also includes compounds in order to show that epenthesis is not attested anywhere. 45 The later EMJ form mirube- is due to analogy with other verbs. 
(4) Crasis

a. compounds naga 'long' + iki, 'breath' > nage ${ }_{1} k i_{1}$ 'sorrow' $\left(†\right.$ nagariki $\left.i_{1}\right)$

b. stative $-e_{(7)} r-<a r$ - 'be' $s a k-i_{1}+a r->s^{2} k e_{1} r$ - 'have bloomed' (†saki $\left.r a r-\right)$

c. nominalized form $n a k i_{1}+-a k u>n a k e_{1} k u$ 'the fact that it is absent' $(† n a k i$ raku)

d. proto-Japanese bigrade verbs $a k a$ 'red' + -i $>a k e_{2}$ 'dawn, redden' (†akari)

The $H_{r}$ is thus falsified by empirical evidence on hiatus resolution in OJ and proto-Japanese: There is no evidence of $r$-epenthesis and $/ \mathrm{r} /$ cannot be eliminated from the inventory of proto-Japanese phonemes and simply reduced to the phonetic manifestation of zero in hiatus position.

The hypothesis that $r$ is a secondary development in Japanese, "added in order to increase the distinctive power of words" (Kuginuki 1982: 195, Labrune 1993: 148) is dubious from the point of view of general historical linguistics, and no typological parallel can be drawn in its support. Words can occasionally be replaced in cases of homophony, or sometimes suffixed, but all instances of $/ \mathrm{r} /$ in Japanese can hardly be reduced to such a usually sporadic phenomenon. Some OJ monosyllables did become disyllabic by adjunction of a mora to their right, but that mora often has an onset other than $r$, e.g., $a \sim a s i$ 'foot,' ye yeda 'branch,' nu numa 'swamp,' etc. In any case, with an eight-way vocalic distinction ${ }^{47}$ and four pitch patterns for monosyllables and five main pitch patterns for disyllables, OJ could distinguish between several hundred monosyllable types and several thousand disyllable types. OJ cannot be said to have faced a major homophony crisis.

As we have seen, $/ \mathrm{r} /$ shares many characteristics with the voiced obstruents $/ b, d, g, z /$, which derive from earlier prenasalized ${ }^{*} N C$ sequences. The properties of Japanese $/ \mathrm{r} /$ can also probably be accounted for by diachronic factors, but the typologically and phonetically grounded explanation for the development of voiced obstruents from earlier * $N C$ sequences fundamentally differs from the unusual scenario of the development of $/ \mathrm{r} /$ ex nihilo proposed by the $H_{r}$. A more sensible approach to historical change would choose among the following possible explanations for the word-initial prohibition of $\mathrm{r} / \mathrm{contrasting}$ with its high word-internal frequency:

46 The modern form okiru is the result of a later process of analogical leveling and of replacement of conclusive forms with adnominal ones.

47 The distinction might have not been one of vowels, but a difference between the absence or presence of a medial glide $y$ or $w$.
(5) a. initial $r$-apheresis: ${ }^{*} r>\varnothing / \#$

b. initial vowel prothesis: $\varnothing>V / \# \_r$

c. initial mutation: ${ }^{*} r>X / \#$

d. medial mutation: ${ }^{*} X>r / V \_V$

Hitherto little research has been done on this subject, which therefore remains open to discussion.

Moreover, the $H_{r}$ aims at explaining why the distribution pattern of $/ \mathrm{r} /$ and $/ ' /$ are symmetrically opposed, but it only provides a partial account. The $H_{r}$ is unable to explain why in the first place /'/ is so frequent wordinitially. On the other hand, the above hypotheses of $r$ apheresis or vowel prothesis would be able to account for that fact.

\section{Formal analysis}

The $H_{r}$ tries to give a formal account of $r$-epenthesis in Japanese and of its historical phonologization within the framework of Optimality Theory (OT). OT being a theory of phonological computation rather than one of representation, the fact that an OT analysis is possible cannot by itself support a hypothesis on a particular representation, like that proposed by the $H_{r}$ for Japanese $/ \mathrm{r} /$. Actually, the OT analysis presented by the $H_{r}$ proves to be flawed in several aspects, which casts further doubt on the very plausibility of the $H_{r}$.

\subsection{Emptiness}

The definition of $/ \mathrm{r} /$ as an "an empty root node," "totally featureless $[. .$.$] even for the major class features"$ (Labrune 2014: 14), attached to an onset skeletal slot, poses an important question for phonological theory. Whether a totally empty root node is a well-formed phonological object and whether it can differ from an empty skeletal slot have not been extensively discussed in the literature as far as I know. Since the $H_{r}$ does not elaborate on this issue, the proposed analysis remains tentative.

Concerning /'/, the "zero" or "empty" onset, no formal definition in terms of phonological structure is given. From a formal (mathematical) point of view, zero (nothing) is different from the empty set $(\{\}$ or $\varnothing$ ), and similarly the absence of an onset is not equivalent to the existence of an onset position not linked to segmental material. At least three representations are possible for I'l within the $H_{r}$ : (a) The absence of an onset, (b) an empty onset slot not linked to any segmental material, and (c) an onset slot linked to an empty feature matrix. ${ }^{48}$

48 This is analogous to the difference between nothing, the empty set, and the singleton set containing the empty set $(\{\varnothing\})$. 
Within the $H_{r}$, vowel-initial words (/\#'V/) violate the ONSET but not the ALIGN constraint, which implies that vowel-initial syllables have no onset position at all. This is in contradiction with the characterization of /'/ as an "empty initial" (Labrune 2014: 5-6) and of /'V/ as containing an empty onset position and as "structurally incomplete" within a strictly binary model (Labrune 2012: 162).

If vowel-initial syllables indeed have an empty position, then it implies that, without further constraints, empty onsets should not violate ONSET. Nothing then would trigger epenthesis in either initial or wordinternal vowel-initial syllables (6).

\section{(6) Evaluation with empty onsets}

\begin{tabular}{|lc||c|c|c|c|}
\hline \multicolumn{2}{|c||}{$/$ 'V'Vl } & ALIGN & OnSET & MAXIO & DePIO \\
\hline \hline a. & 'V & & & $* !$ & \\
\hline b. & 'V'V & & & & \\
\hline c. & CVCV & & & $* ! *$ \\
\hline d. & 'VCV & & & $* !$ \\
\hline
\end{tabular}

The $H_{r}$ and the strictly binary model of prosodic units in Japanese are thus incompatible. Whatever exact analysis is chosen, other problems persist which cast doubt upon $r$-epenthesis in Japanese.

\subsection{Featural agreement}

The second constraint invoked by the $H_{r}$ is featural agreement, which states that adjacent segments cannot differ in their value for a given feature $F$ ( $\left.{ }^{*}[\alpha F][-\alpha F]\right)$. Here, the $H_{r}$ considers $/ \mathrm{r} /$ to agree with vowels for the features [+sonorant], [+voiced], [-nasal], and [+continuant], so that it emerges as the optimal epenthetic candidate in hiatus position (Labrune 2014: 17-18).

The treatment of featural agreement by the $H_{r}$ suffers from two problems. First, it argues that Japanese $/ \mathrm{r} /$ is specified with the feature [+continuant], which would agree with the surrounding vowels, but the usual realization of Japanese / $\mathrm{r}$ / is a tap, and there is no evidence that this was not the case in earlier Japanese too. Taps are usually classified as [-continuant] (Hall 1997, 2007; Wiese 2011) since they are pronounced with a closure, which has been verified instrumentally for Japanese (Kokuritsu kokugo kenkyūjo 199o: 491-493). Whatever ranking is adopted, [-continuant] $/ \mathrm{r} /$ would fail to surface in favor of the [+continuant] glides $/ \mathrm{y} /$ and $/ \mathrm{w} /$ (7).

Second, the $H_{r}$ 's featural agreement includes all relevant manner and laryngeal features, but it crucially omits the major class feature [ \pm consonantal], even though $[ \pm$ sonorant $]$ is included. Since both approximants and vowels are [-consonantal], [+consonantal] $/ \mathrm{r} /$ cannot surface as the optimal candidate (7).

\section{(7) Featural agreement}

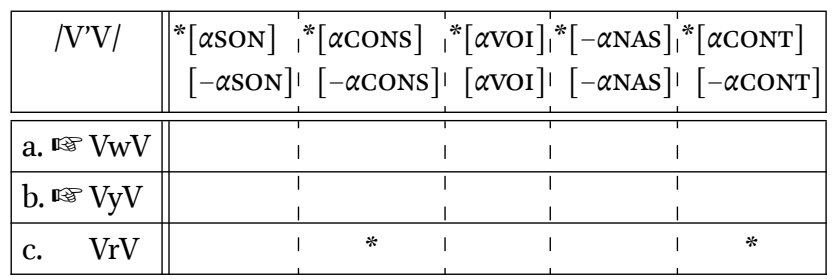

\subsection{Harmony scale}

Next, the $H_{r}$ invokes the universal harmony scale ${ }^{*}$ LABIAL, " DORSAL $\gg$ * CORONAL, which states that coronals are universally less marked than both labials and dorsals. This enables the $H_{r}$ to eliminate both $/ \mathrm{y} /$ and $/ \mathrm{w} /$ in favor of $/ \mathrm{r} /$ as the optimal epenthetic candidate. This use of the harmony scale, however, crucially depends on the specification of $/ y /([j])$ as [DORSAL] and not [CORONAL], but this stands in contradiction with the general consensus that palatal segments are [CORONAL] (see Hall 2007, 2011 and references therein).

Though [j] is a dorso-palatal segment, it involves the ante-dorsal part of the tongue as an articulator (Catford 2001: 90) and thus qualifies as a coronal sound, since coronals are defined as those sounds "involving a constriction formed by the front of the tongue" (Clements \& Hume 1995: 277). The recognition of [j] as a coronal is also supported by the fact that it is an alveolopalatal in many languages (Recasens 2013). The evaluation by the $H_{r}$ is thus at least controversial, and the emergence of $/ \mathrm{r} /$ instead of $/ \mathrm{y} /$ cannot be readily accepted (8).

\section{(8) Harmony scale}

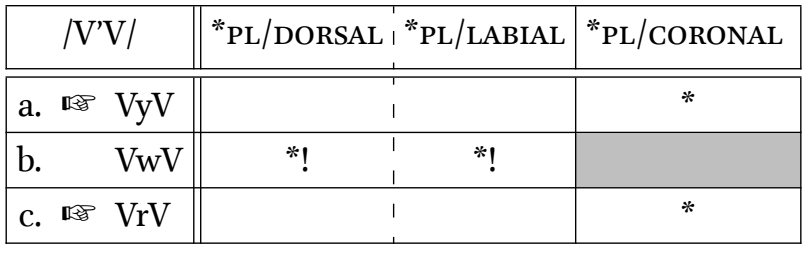

Overall, the best candidate for epenthesis is thus not $/ \mathrm{r} /$, but $/ \mathrm{y} /$, followed by $/ \mathrm{w} /$. This is why there is simply no synchronically active process that inserts $/ \mathrm{r} /$ in Japanese, and no clear historical example of $r$ epenthesis attested. This also explains why vowel hiatus in MSJ can be resolved by epenthesis of an approximant, like baai [ba:i] [bajai] [bawai] 'case' or shiawase [ciawase] [6ijawase] 'happiness' (Martin 1952: 13, Labrune 2012: 45). Comparable examples involving $/ \mathrm{r} /$ are wanting. 


\subsection{Lexicon Optimization}

The $H_{r}$ proposes that Japanese $/ \mathrm{r} /$ is an unspecified, i.e., "totally featureless" (Labrune 2014: 14)) consonant, but underspecification has always been an actively debated issue in generative phonology, and it is particularly problematic within OT. The principle of Lexicon Optimization (LO, Prince \& Smolensky 2004: 225-231) postulates that inputs that are the most faithful to their outputs will be selected as underlying representations, and fully specified representations are thus favored over underspecified ones by default. ${ }^{49}$ One consequence of that principle is that epenthetic segments are by default bound to be interpreted by learners as underlying segments. Cast within the OT framework, the $H_{r}$ calls upon LO in a two-step diachronic scenario: First, zero in the input is mapped to an output rhotic, and second, that rhotic is analyzed as an underlying segment and added to the phonological inventory due to LO (Labrune 2014: 21). 50

Still, no formal device is proposed to ensure that the surface rhotic is not part of the underlying representation during step 1 of the $H_{r}$. Within the OT analysis proposed, it is hard to imagine how step 1 could ever have synchronically existed unless some constraint(s) prevent(s) $r$ from being analyzed as part of the input. The set of constraints posited by the $H_{r}$ entails that the epenthesis of $r$ instantly leads to its reanalysis as underlyingly present. Even after LO, no solution is provided to the underspecification problem, and nothing thus prevents a fully specified $/ \mathrm{r} /$ to be posited as the input rather than the $H_{r}$ 's featureless $/ \mathrm{r} /$. For the $H_{r}$ " [f] eatures such as $[ \pm$ continuant $],[ \pm$ lateral $],[ \pm$ retroflex $]$ are supposedly acquired at a later stage of the derivation" (Labrune 2014: 14), but this is incompatible with standard OT, a non-derivational theory of phonology (Prince \& Smolensky 2004). The central issue of the very possibility of a featureless $/ \mathrm{r} /$ is thus left completely unaddressed by the $H_{r}$.

\section{Conclusions}

A reexamination of all the evidence presented in favor of the unique featureless status of $/ r /$ in Japanese leads to the rejection of that hypothesis. Only two characteristics can be accepted as peculiar to /r/. First, it resists gemination in mimetic adverbs, but this at most suggests the possibility of its lack of underlying place specification. Second, though the $H_{r}$ 's claims about its frequency should be tempered, /r/ exhibits a distributional asymmetry: it is highly frequent in word-internal posi-

49 See the discussion in Krämer (2012) and references therein.

$5^{\circ}$ The $H_{r}$ thus proposes that an original zero was reanalyzed as an empty consonant, but how these two differ remains completely unexplained. tion but absent from word-initial position. This requires a plausible historical explanation based on phonetics, while the spontaneous emergence of $/ \mathrm{r} /$ posited by the $H_{r}$ is not grounded in either perception or production. All other arguments adduced by the $H_{r}$ are either inaccurate or do not uniquely characterize $/ \mathrm{r} /$, and are thus invalid, so that alternative accounts that do not refer to the featural content of $/ \mathrm{r} /$ prove to be preferable. The historical scenario proposed by the $H_{r}$ not only lacks support from direct, typological, or phonetic evidence, it also actually entails wrong predictions. Once several necessary amendments and modifications are made, the formal treatment within the framework of Optimality Theory does not generate the data expected by the $H_{r}$. The $H_{r}$ thus fails to achieve both observational and descriptive adequacy.

All of the above does not deny that $/ r /$ has a peculiar place within the Japanese phonological system, nor that the characteristics of $/ \mathrm{r} /$ are to be explained by the historical sound changes that affected it. However, rather than "unique," the label "isolated" better describes it. It is the only liquid in the system and it does not enter into correlations of voicing $(/ \mathrm{p} /-/ \mathrm{b} /, / \mathrm{t} /-/ \mathrm{d} /, / \mathrm{k} /-/ \mathrm{g} /, / \mathrm{s} /-/ \mathrm{z} /)$ or place $(/ \mathrm{m} /-/ \mathrm{n} /, / \mathrm{w} /-/ \mathrm{y} /, / \mathrm{p} /-/ \mathrm{t} /, / \mathrm{b} /-/ \mathrm{d} /$, etc. $)$ with other consonants. In the terms of traditional functional phonology, Japanese / $\mathrm{r}$ / does not form an exclusive opposition with any another consonant, i.e., there is no phoneme that differs from $/ \mathrm{r}$ / by only one relevant feature and that shares with it a subset of its features that is not shared by any other consonant. From this perspective, Japanese $/ \mathrm{r}$ / is thus not really unmarked, but simply does not take part in markedness oppositions, and it is underspecified since the single feature "liquid" suffices to distinguish it from all other consonants. The peculiar isolated status of / $\mathrm{r}$ / was already noticed by Trubetzkoy (1939: 66), who also interpreted that status as the cause of the phonetic variability of $/ \mathrm{r} /{ }^{51}$ Labrune (2012: $6,85^{-87}$ ) was right to remind us that we can still benefit from carefully studying the rich tradition of Japanese research on linguistics, but that is also true for the rich European tradition of functionalist and structuralist linguistics.

\section{Acknowledgments}

I wish to thank Shigeto Kawahara for his very useful comments on an earlier version of this article and for his suggestions about statistical tests. I also thank Sayaka Irie and T. A. Hall, who kindly sent me a copy of their work. I am also grateful to two anonymous reviewers for

51 Actually, Trubetzkoy analyzes the Japanese palatalized consonants as unitary phonemes and not as $C y$ sequences as is usually done elsewhere, so that, in his analysis, $/ \mathrm{r} /$ is opposed to palatalized $/ \mathrm{r}^{\prime} /$ and the two form an exclusive and correlative opposition. See also Akamatsu (2000). 
suggesting many useful improvements to this article. A third anonymous reviewer also provided me with the occasion to clarify and strengthen my argumentation by perseveringly challenging all aspects of the method, logic and empirical evidence used in this article.

\section{References}

Akamatsu, Tsutomu. 1997. Japanese phonetics: Theory and practice. München: Lincom Europa.

Akamatsu, Tsutomu. 200o. Japanese phonology: A functional approach. München: Lincom Europa.

Alpher, Barry. 2004. Pama-Nyungan: Phonological reconstruction and status as a phylogenetic group. In Claire Bowern \& Harold Koch (eds.), Australian languages: Classification and the comparative method, 93-126. Amsterdam; Philadelphia: John Benjamins.

Anderson, Gregory D. S. 1997. Burushaski phonology. In Alan S. Kaye (ed.), Phonologies of Asia and America (including the Caucasus): Volume 1, 1021-1041. Winona Lake: Eisenbrauns.

Arai, Takayuki. 2013. On why Japanese /r/ sounds are difficult for children to acquire. In Frédéric Bimbot, Christophe Cerisara, Cécile Fougeron, Guillaume Gravier, Lori Lamel, François Pellegrino \& Pascal Perrier (eds.), Interspeech 2013, 2445-2449. ISCA.

Arisaka, Hideyo. 1955. Jōdai on'in kō [A study of Old Japanese phonology]. Tokyo: Sanseidō.

Batchelder, Eleanor Olds. 1999. Rule or rote? Native-speaker knowledge of Japanese verb inflection. In Proceedings of the Second International Conference on Cognitive Science (ICCS), 141-146. Tokyo.

Blevins, Juliette. 2008. Natural and unnatural sound patterns: A pocket field guide. In Klaas Willems \& Ludovic De Cuypere (eds.), Naturalness and iconicity in language, 121-148. Amsterdam; Philadelphia: John Benjamins.

Bloch, Bernard. 1946. Studies in Colloquial Japanese I: Inflection. Journal of the American Oriental Society 66(2). 97-109.

Bloomfield, Leonard. 1925. On the sound system of Central Algonquian. Language 1(4). 130-156.

Blust, Robert \& Stephen Trussel. 2010. Austronesian comparative dictionary. http://www. trussel2. com/acd/.

Canty, Angelo \& B. D. Ripley. 2016. boot: Bootstrap R (S-Plus) functions. https://cran.r-project.org/web/packages/boot/. R package version 1.3-18.

Catford, John C. 2001. A practical introduction to phonetics. Oxford; New York: Oxford University Press.

Cincius, Vera I (ed.). 1975-1977. Sravnitel'nyj slovar' tungusoman'čžurskix jazykov: Materialy k ètimologičeskomu slovarju. Leningrad: Nauka.

Clements, G. N. \& Elizabeth V. Hume. 1995. The internal organization of speech sounds. In John A. Goldsmith (ed.), The handbook of phonological theory, 245-306. Cambridge: Blackwell.

Davison, Anthony C. \& David V. Hinkley. 1997. Bootstrap methods and their applications. Cambridge: Cambridge University Press.

Den, Yasuharu, Toshinobu Ogiso, Hideki Ogura, Atsushi Yamada, Nobuaki Minematsu, Kiyotaka Uchimoto \& Hanae
Koiso. 2007. Kōpasu nihongogaku no tame no gengo shigen: Keitaiso kaisekiyō denshika jisho no kaihatsu to sono oyō [Resources for Japanese corpus linguistics: Development and use of an electronic dictionary for morphological parsing]. Nihongo Kagaku 22. 101-122.

Efron, Bradley \& Robert J. Tibshirani. 1993. An introduction to the bootstrap. New York: Chapman \& Hall.

Flack, Kathryn Gilbert. 2007. The sources of phonological markedness. Amherst: University of Massachusetts Amherst dissertation.

Frellesvig, Bjarke. 2008. On reconstruction of protoJapanese and pre-Old Japanese verb inflection. In Bjarke Frellesvig \& John Whitman (eds.), Proto-Japanese: Issues and prospects, 175-192. Amsterdam; Philadelphia: John Benjamins.

Frellesvig, Bjarke. 2010. A history of the Japanese language. Cambridge: Cambridge University Press.

Georg, Stefan. 2003. Japanese, the Altaic theory, and the limits of language classification. In Vovin \& Osada (2003) 429449.

Hagège, Claude \& André Haudricourt. 1978. La phonologie panchronique. Paris: PUF.

Hall, T. A. 1997. The phonology of coronals. Amsterdam: John Benjamins.

Hall, T. A. 200o. Typological generalizations concerning secondary palatalization. Lingua $110(1) .1-25$.

Hall, T. A. 2007. Segmental features. In Paul de Lacy (ed.), The Cambridge handbook of phonology, 311-334. Cambridge: Cambridge University Press.

Hall, T. A. 2011. Coronals. In van Oostendorp et al. (2011) 267287 .

Hall, T. A. 2013. How common is r-epenthesis? Folia Linguistica $47(1) \cdot 55^{-87}$.

Hall, T. A. \& Silke Hamann. 2010. On the cross-linguistic avoidance of rhotic plus high front vocoid sequences. Lingua 120(7). 1821-1844.

Hamano, Shoko. 1998. The sound-symbolic system ofJapanese. Stanford: CSLI.

Hamilton, Philip James. 1996. Phonetic constraints and markedness in the phonotactics of Australian Aboriginal languages. Toronto: University of Toronto dissertation.

Hattori, Shirō. 1961. Akusento-so, onsetsu kōzō, kōon onso [Accenteme, syllable structure, laryngeal phoneme]. Onsei no Kenkyū 9. 1-31.

Hock, Hans. 1991. Principles of historical linguistics. Berlin; New York: Mouton de Gruyter.

Hockett, Charles F. 1955. A manual of phonology. Baltimore: Waverly Press.

Ichimura, Larry K. 2006. Anti-homophony blocking and its productivity in transparadigmatic relations. Boston: Boston University dissertation.

Irie, Sayaka. 1996. Gendai Nihongo ni okeru wago sanpaku meishi ni tsuite: Shutsugen ichi ni mita onso bunpu no bunseki to kōsatsu [On three-mora native nouns in Modern Japanese: An analysis and study of the distribution of phonemes according to their position]. Dōshisha Kokubungaku 43. 97-108.

Irie, Sayaka. 2012. Nihongo no onso no bunpu/hairetsu ni kansuru rekishiteki kenkyū [A historical study on the 
distribution and phonotactics of Japanese phonemes]. Dōshisha Nihongo Kenkyū Bekkan 1.

Jakobson, Roman. 1941. Kindersprache, Aphasie und allgemeine Lautgesetze. Uppsala: Almqvist \& Wiksell.

Johanson, Lars. 1998. The structure of Turkic. In Lars Johanson \& Éva Á. Csató (eds.), The Turkic languages, 30-66. London; New York: Routledge.

Karimata, Shigehisa. 1999. Onsei no men kara mita Ryūkyū shohōgen [The Ryukyuan dialects seen from the point of view of phonetics]. In Gengogaku kenkyūkai (ed.), Kotoba no kagaku 9, 13-85. Tokyo: Mugi shobō.

Kawahara, Shigeto. 2007. Sonorancy and geminacy. University of Massachusetts Occasional Papers in Linguistics 32. 145186.

Kawahara, Shigeto. 2015. Japanese /r/ is not feature-less: A rejoinder to Labrune (2014). Open Linguistics 1(1). 432-443.

Kawahara, Shigeto, Hajime Ono \& Kiyoshi Sudo. 20o6. Consonant coocurrence restrictions in Yamato Japanese. In Timothy Vance \& Kimberley Jones (eds.),Japanese/Korean linguistics 14, 27-38. Stanford: CSLI Publications.

Kokuritsu kokugo kenkyūjo. 1984-1985. Goi no kenkyū to kyōiku [Researching and teaching the lexicon]. Tokyo: Ōkurashō insatsu kyoku. 2 vols.

Kokuritsu kokugo kenkyūjo (ed.). 199o. Nihongo no boin, shiin, onsetsu: Chōon undō no jikken onseigaku kenkyū [The vowels, consonants, and syllables of Japanese: An experimental phonetic study of articulatory movements]. Tokyo: Shūei shuppan.

Krishnamurti, Bhadriraju. 2003. The Dravidian languages. Cambridge; New York: Cambridge University Press.

Krämer, Martin. 2012. Underlying representations. Cambridge; New York: Cambridge University Press.

Kuginuki, Tōru. 1982. Jōdai Nihongo ragyōon kō [A study on the $r$ sound of Old Japanese]. Toyama Daigaku Jinbungakubu Kiyō 6. 192-206.

Kümmel, Martin Joachim. 2007. Konsonantenwandel: Bausteine zu einer Typologie des Lautwandels und ihre Konsequenzen für die vergleichende Rekonstruktion. Wiesbaden: Reichert.

Kupchik, John E. 2013. Hypermetricality and synchronic vowel elision in hiatus contexts in Eastern Old Japanese. Cahiers de Linguistique Asie Orientale 42(1). 2-32.

Kurisu, Kazutaka. 2009. Palatalisability via feature compatibility. Phonology 26(3). 437-475.

Labrune, Laurence. 1993. À propos d'un trait typologique du japonais: L'absence de $r$ à l'initiale des mots indépendants de Yamato kotoba. Ebisu: Études japonaises 2. 7-21.

Labrune, Laurence. 1998. De l'iconicité en japonais: Suffixes en $r+$ voyelle et réduplication. Cahiers de Linguistique Asie Orientale 27(1). 79-118.

Labrune, Laurence. 2012. The phonology ofJapanese. Oxford: Oxford University Press.

Labrune, Laurence. 2014. The phonology of Japanese /r/: A panchronic account. Journal of East Asian Linguistics 23(1). $1-25$.

Ladefoged, Peter \& Ian Maddieson. 1996. The sounds of the world's languages. Oxford: Blackwell.

Lawrence, Wayne P. 200o. Shiin o koete okoru boin no yūgō: Ryūkyū hōgen ni okeru genshō o chūshin ni [Vowel coales- cence across consonants: The phenomenon in Ryukyuan dialects]. Onsei Kenkyū 4(1).55-6o.

Lee, Ki-Moon \& S. Robert Ramsey. 2011. A history of the Korean language. Cambridge: Cambridge University Press.

Martin, Samuel E. 1952. Morphophonemics of Standard Colloquial Japanese. Baltimore: Linguistic Society of America.

Martin, Samuel E. 1966. Lexical evidence relating Korean to Japanese. Language 42(2). 185-251.

Martin, Samuel E. 1987. The Japanese language through time. New Haven; London: Yale University Press.

Matasović, Ranko. 2012. Areal typology of proto-IndoEuropean. Transactions of the Philological Society $110(2)$. 283-310.

McCarthy, John J. 1993. A case of surface constraint violation. Canadian Journal of Linguistics/Revue Canadienne de Linguistique 38(2). 169-195.

McCawley, James D. 1968. The phonological component of a grammar ofJapanese. The Hague; Paris: Mouton.

Mester, Armin \& Junko Itō. 1989. Feature predictability and underspecification: Palatal prosody in Japanese mimetics. Language 65. 258-293.

Miyajima, Tatsuo, Tai Suzuki, Hisao Ishii \& Seiya Abe (eds.). 2014. Nihon koten taishō bunrui goi hyō [Comparative table of the classified lexicon of Classical Japanese]. Tokyo: Kasama shoin.

Miyake, Marc H. 2003. Old Japanese: A phonetic reconstruction. London; New York: RoutledgeCurzon.

Miyara, Tōsō. 1980-1981 [1930]. Yaeyama goi [Yaeyama lexicon]. Tokyo: Daichi shobō. 2 vols.

Nakamura, Yukihiko, Masao Okami \& Atsuyoshi Sakakura (eds.). 1982-1999. Kadokawa kogo daijiten [Great dictionary of earlier Japanese]. Tokyo: Kadokawa shoten.

Nugteren, Hans. 2011. Mongolic phonology and the QinghaiGansu languages. Leiden: Universiteit Leiden dissertation. van Oostendorp, Marc, Colin J. Ewen, Elizabeth Hume \& Keren Rice (eds.). 2011. The Blackwell companion to phonology. Malden: Wiley-Blackwell.

Otoguro, Ryo. 2009. Surface-oriented morphological network. Jinbun Ronshū 48. 240-219.

Pellard, Thomas. 2013. Ryukyuan perspectives on the protoJaponic vowel system. In Bjarke Frellesvig \& Peter Sells (eds.), Japanese/Korean Linguistics 20, 81-96. Stanford: CSLI Publications.

Pellard, Thomas. 2015. The linguistic archaeology of the Ryukyu islands. In Patrick Heinrich, Shinsho Miyara \& Michinori Shimoji (eds.), Handbook of the Ryukyuan languages: History, structure, and use, 13-37. Berlin; Boston: De Gruyter Mouton.

Pellard, Thomas. 2016. Nichiryū sogo no bunki nendai [The date of separation of the proto-Japonic language]. In Takubo et al. (2016) 99-124.

Podesva, Robert. 2002. Segmental constraints on geminates and their implications for typology. In 76th Annual Meeting of the Linguistic Society of America, San Francisco. 3-6 January 2002.

Prince, Alan \& Paul Smolensky. 2004. Optimality theory: Constraint interaction in generative grammar. Malden: Blackwell Publishing.

R Core Team. 2015. R: A language and environment for statis- 
tical computing. R Foundation for Statistical Computing Vienna, Austria. http://www.R-project.org/.

Recasens, Daniel. 2013. On the articulatory classification of (alveolo)palatal consonants. Journal of the International Phonetic Association 43(1). 1-21.

Ross, Malcolm D. 1992. The sound of proto-Austronesian: An outsider's view of the Formosan evidence. Oceanic Linguistics 31(1). 23-64.

Russell, Kerri. 2003. Contraction and monophtongization in Old Japanese. In Vovin \& Osada (2003) 511-538.

Saitō, Yoshio. 2003. Gendai Nihongo no onsei: Bunsetsuon to onsei kigō [The phonetics of Modern Japanese: Segments and phonetic symbols]. In Zendō Uwano (ed.), Asakura Nihongo kōza 3: Onsei, on'in [The Asakura course in Japanese 3: Phonology], 1-21. Tokyo: Asakura shoten.

Schourup, Lawrence \& Ikuhiro Tamori. 1992. Japanese palatalization in relation to theories of restricted underspecification. Gengo Kenkyū 101. 107-145.

Shibatani, Masayoshi. 199o. The languages of Japan. Cambridge: Cambridge University Press.

Staroverov, Petr. 2014. Splitting theory and consonant epenthesis. New Brunswick: Rutgers University dissertation.

Svantesson, Olaf, Anna Tsendina, Anastasia Karlsson \& Vivan Franzén. 2005. The phonology of Mongolian. Oxford; New York: Oxford University Press.

Takubo, Yukinori, John Whitman \& Tatsuya Hirako (eds.). 2016. Ryūkyū shogo to Kodai Nihongo: Nichiryū sogo no saiken ni mukete [The Ryukyuan languages and Ancient Japanese: Toward the reconstruction of proto-Japonic]. Tokyo: Kuroshio shuppan.

Tamori, Ikuhiro \& Lawrence Schourup. 1999. Onomatope: Keitai to imi [Onomatopeia: Form and meaning]. Tokyo: Kuroshio shuppan.

Trubetzkoy, N. S. 1939. Grundzüge der Phonologie. Prague: Jednota československých matematiků a fyziků.

Ueda, Isao \& Stuart Davis. 20o1. The acquisition of Japanese "r". Gengo Kenkyū 119. 111-139.

Uemura, Yukio. 1997. Ryūkyū rettō no gengo: Sōsetsu [The languages of the Ryukyu Islands: General introduction]. In Takashi Kamei, Rokurō Kōno \& Ei'ichi Chino (eds.), Nihon rettō no gengo [The languages of the Japanese archipelago], 311-354. Tokyo: Sanseidō.

Uffmann, Christian. 2007. Intrusive [r] and optimal epenthetic consonants. Language Sciences 29. 451-476.

Unger, J. Marshall. 1975. Studies in early Japanese morphophonemics. New Haven: Yale University dissertation.

Vance, Timothy J. 1987. An introduction toJapanese phonology. Albany: State University of New York Press.

Vance, Timothy J. 1991. A new experimental study of Japanese verb morphology. Journal of Japanese Linguistics 13. 145156.

Vance, Timothy J. 2008. The sounds of Japanese. Cambridge: Cambridge University Press.

Vovin, Alexander. 2005a. A descriptive and comparative grammar of Western Old Japanese: 1, Sources, script and phonology, nominals. Folkestone: Global Oriental.

Vovin, Alexander. 2005b. The end of the Altaic controversy. Central Asiatic Journal 49(1). 71-132.

Vovin, Alexander. 2009. A descriptive and comparative gram- mar of Western Old Japanese: 2, Adjectives, verbs, adverbs, conjunctions, particles, postpositions. Folkestone: Global Oriental.

Vovin, Alexander \& Toshiki Osada (eds.). 2003. Nihongo keitōron no genzai (Perspectives on the origins of the Japanese language). Kyoto: Kokusai Nihon bunka sentā.

Wenck, Günther. 1966. The phonemics ofJapanese: Questions and attempts. Wiesbaden: Harrassowitz.

Whitman, John. 2012. The relationship between Japanese and Korean. In Nicolas Tranter (ed.), The languages of Japan and Korea, 24-38. New York: Routledge.

Whitman, John. 2016. Nichi-ryū sogo no on'in taikei to rentaikei, izenkei no kigen [The phonological system of proto-Japonic and the origin of the realis and adnominal forms]. In Takubo et al. (2016).

Whitman, John B. 1985. The phonological basis for the comparison of Japanese and Korean: Harvard University dissertation.

Wiese, Richard. 2011. The representation of rhotics. In van Oostendorp et al. (2011) 711-729.

Wolff, John U. 2010. Proto-Austronesian phonology with glossary. Ithaca: Cornell Southeast Asia Program Publications.

Yamaguchi, Yoshinori. 1974. Kodai Nihongo ni okeru gotō shiin no datsuraku [Word-initial consonant loss in Old Japanese]. Kokugogaku 98.1-15. 